\title{
An assessment of the Arctic Ocean in a suite of interannual CORE-II simulations. Part I: Sea ice and solid freshwater
}

Qiang Wang ${ }^{\mathrm{a}, *}$, Mehmet Ilicak ${ }^{\mathrm{b}}$, Rüdiger Gerdes ${ }^{\mathrm{a}}$, Helge Drange ${ }^{\mathrm{c}}$, Yevgeny Aksenov $^{\mathrm{d}}$, David A Bailey ${ }^{\mathrm{e}}$, Mats Bentsen ${ }^{\mathrm{b}}$, Arne Biastoch ${ }^{\mathrm{f}}$, Alexandra Bozec ${ }^{\mathrm{g}}$, Claus Böning ${ }^{\mathrm{f}}$, Christophe Cassou ${ }^{\mathrm{h}}$, Eric Chassignet ${ }^{\mathrm{g}}$, Andrew C. Coward ${ }^{\mathrm{d}}$, Beth Curry ${ }^{\mathrm{i}}$, Gokhan Danabasoglu ${ }^{\mathrm{e}}$, Sergey Danilov ${ }^{\mathrm{a}}$, Elodie Fernandez ${ }^{\mathrm{h}}$, Pier Giuseppe Fogli ${ }^{\mathrm{j}}$, Yosuke Fujii ${ }^{\mathrm{k}}$, Stephen M. Griffies ${ }^{\mathrm{l}}$, Doroteaciro Iovino ${ }^{\mathrm{j}}$, Alexandra Jahn ${ }^{\mathrm{e}, \mathrm{m}}$, Thomas Jung, ${ }^{\mathrm{a}, \mathrm{n}}$, William

G. Large ${ }^{\mathrm{e}}$, Craig Lee ${ }^{\mathrm{i}}$, Camille Lique, ${ }^{\mathrm{o}, \mathrm{p}}$, Jianhua Lu ${ }^{\mathrm{g}}$, Simona Masina ${ }^{j}$, A.J. George Nurser $^{\mathrm{d}}$, Benjamin Rabe ${ }^{\mathrm{a}}$, Christina Roth ${ }^{\mathrm{f}}$, David Salas y Mélia ${ }^{\mathrm{q}}$, Bonita L. Samuels ${ }^{1}$, Paul Spence ${ }^{\mathrm{r}, \mathrm{s}}$, Hiroyuki Tsujinok ${ }^{\mathrm{k}}$, Sophie Valcke ${ }^{\mathrm{h}}$, Aurore Voldoire ${ }^{\mathrm{q}}$, Xuezhu Wang ${ }^{\mathrm{a}}$, Steve G. Yeager

${ }^{a}$ Alfred Wegener Institute, Helmholtz Centre for Polar and Marine Research (AWI), Bremerhaven, Germany

${ }^{b}$ Uni Research Ltd., Bergen, Norway

${ }^{c}$ University of Bergen, Bergen, Norway

${ }^{d}$ National Oceanography Centre (NOC), Southampton, SO14 3ZH, UK

${ }^{e}$ National Center for Atmospheric Research (NCAR), Boulder, CO, USA

${ }^{f}$ GEOMAR Helmholtz Centre for Ocean Research, Kiel, Germany

${ }^{g}$ Center for Ocean-Atmospheric Prediction Studies (COAPS), Florida State University, Tallahassee, $F L, U S A$

${ }^{h}$ Centre Européen de Recherche et de Formation Avancée en Calcul Scientifique (CERFACS), Toulouse, France

${ }^{i}$ Applied Physics Laboratory, University of Washington, seattle, Washington, USA

${ }^{j}$ Centro Euro-Mediterraneo sui Cambiamenti Climatici (CMCC), Bologna, Italy

${ }^{k}$ Meteorological Research Institute (MRI), Japan Meteorological Agency, Tsukuba, Japan

${ }^{l}$ NOAA Geophysical Fluid Dynamics Laboratory (GFDL), Princeton, NJ, USA

${ }^{m}$ Department of Atmospheric and Oceanic Sciences and Institute of Arctic and Alpine Research, University of Colorado, Boulder, CO, USA

${ }^{n}$ Institute of Environmental Physics, University of Bremen, Bremen, Germany

${ }^{\circ}$ Department of Earth Sciences, University of Oxford, Oxford, UK

${ }^{p}$ Laboratoire de Physique des Océans, Ifremer, centre de Brest, Plouzané, France

${ }^{q}$ Centre National de Recherches Météorologiques (CNRM), Toulouse, France

${ }^{r}$ Climate Change Research Centre, University of New South Wales, Sydney, Australia

${ }^{s}$ ARC Centre of Excellence for Climate System Science, University of New South Wales, Sydney, Australia

\begin{abstract}
\footnotetext{
*Corresponding author

Email address: Qiang.Wang@awi.de (Qiang Wang)
}

The Arctic Ocean simulated in fourteen global ocean-sea ice models in the framework of the Coordinated Ocean-ice Reference Experiments, phase II (CORE II) is analyzed. The focus is on the Arctic sea ice extent, the solid freshwater (FW) sources and solid 
freshwater content (FWC). Available observations are used for model evaluation. The variability of sea ice extent and solid FW budget is more consistently reproduced than their mean state in the models. The descending trend of September sea ice extent is well simulated in terms of the model ensemble mean. Models overestimating sea ice thickness tend to underestimate the descending trend of September sea ice extent. The models underestimate the observed sea ice thinning trend by a factor of two. When averaged on decadal time scales, the variation of Arctic solid FWC is contributed by those of both sea ice production and sea ice transport, which are out of phase in time. The solid FWC decreased in the recent decades, caused mainly by the reduction in sea ice thickness. The models did not simulate the acceleration of sea ice thickness decline, leading to an underestimation of solid FWC trend after 2000. The common model behaviour, including the tendency to underestimate the trend of sea ice thickness and March sea ice extent, remains to be improved.

Keywords: Arctic Ocean, Sea ice, Freshwater, CORE II atmospheric forcing

\section{Contents}

\begin{tabular}{lll}
\hline & Introduction & 3
\end{tabular}

1.1 Participating models $\ldots \ldots \ldots \ldots$. . . . . . . . . . . . . . 5

1.2 Basic concepts . . . . . . . . . . . . . . . . . . . . . . 8

1.3 Model spin-up . . . . . . . . . . . . . . . . . . . . . . . . . . . . . . . 10

$\begin{array}{lll}2 & \text { Sea ice extent and concentration } & 11\end{array}$

2.1 Mean state . . . . . . . . . . . . . . . . . . . . . . . . . 11

2.2 Variability and trend $\ldots \ldots \ldots \ldots$. . . . . . . . . . . . . . 13

2.3 Sea ice extent in Barents Sea . . . . . . . . . . . . . . . . . . . . . . 17

2.4 Summary on the model ensemble mean of sea ice extent. . . . . . . . . . 19

\begin{tabular}{lll}
\hline 3 & Solid freshwater & 21
\end{tabular}

3.1 Mean state . . . . . . . . . . . . . . . . . . . . . . . . 21

3.1 .1 Solid freshwater sources . . . . . . . . . . . . . . . . . . . . . . 21

3.1 .2 Solid freshwater content . . . . . . . . . . . . . . . . . . . . 23 
3.2 .1 Solid freshwater sources . . . . . . . . . . . . . . . . . . . . . . 29

3.2 .2 Solid freshwater content . . . . . . . . . . . . . . . . . . . . 32

3.3 Seasonal variability $\ldots \ldots \ldots \ldots$. . . . . . . . . . . . . . . . . . . 37

3.4 Summary on the model ensemble mean of solid freshwater . . . . . . . . 38

Appendix A. Sea ice models used in the CORE-II simulations

Appendix B. Definition of freshwater content and transport

\section{References}

\section{Introduction}

The Arctic Ocean is an important component of the climate system. It closely interacts with the atmosphere at the surface and is connected with the large scale ocean circulation through its gateways. Sea ice, a unique feature of the high latitude oceans, modifies the planetary albedo and impacts on the air-sea heat, momentum, mass and gas exchange. Arctic sea ice has retreated significantly in recent years Kwok and Rothrock, 2009; Comiso, 2012; Cavalieri and Parkinson, 2012; Stroeve et al., 2012a; Laxon et al., 2013), causing amplified warming in the Arctic region (Serreze and Barry, 2011) and farreaching impact on the Earth System (Bhatt et al. 2014). The Arctic Ocean is a large freshwater $(\mathrm{FW})$ reservoir due to river runoff, net precipitation $(\mathrm{P}-\mathrm{E})$ and $\mathrm{FW}$ import from the Pacific (Serreze et al., 2006; Dickson et al., 2007). The excess FW is exported to the subpolar North Atlantic, which can influence the upper ocean stratification and deep water formation, and thus the meridional overturning circulation (e.g., Aagaard et al., 1985; Goosse et al., 1997; Hakkinen, 1999; Wadley and Bigg, 2002; Jungclaus et al., 2005). At depth the intermediate water leaves the Arctic Ocean through Fram Strait, supplying dense waters that overflow into the Atlantic proper and then feed the North Atlantic Deep Water (Rudels and Friedrich, 2000; Karcher et al., 2011). Because of its essential role in the climate system, understanding the functioning of the Arctic Ocean and predicting its future are among the key topics of climate research. 
Improved understanding of the Arctic Ocean has been achieved by using both observations and numerical simulations (see reviews by Proshutinsky et al., 2011; Haine et al., 2015; Carmack et al., 2015). As model uncertainty can impact on the robustness of both physical mechanisms and climate changes inferred from model simulations, assessment of model performance is necessary. Model intercomparison is a useful method to illustrate model consistency and spread, thus helping to identify required model improvements. Model intercomparisons for the Arctic Ocean have been carried out based on both coupled climate models (e.g., Holland et al., 2007; Rawlins et al., 2010; Stroeve et al., 2012a) and forced ocean-ice models (e.g., Holloway et al., 2007; Karcher et al., 2007; Johnson et al., 2007; Jahn et al., 2012a; Johnson et al., 2012). The latter studies are based on models participating in the Arctic Ocean Model Intercomparison Project (AOMIP, Proshutinsky et al., 2011).

In this work we analyze and compare the ocean and sea ice properties in the Arctic Ocean simulated by models participating in the Coordinated Ocean-ice Reference Experiments, phase II (CORE-II) project. Model intercomparison under the CORE-II framework has a few advantages. First, all ocean-ice models are driven by the same atmospheric state, the CORE interannual forcing (Large and Yeager, 2009), and use the same (NCAR) bulk formulae (see the CORE-II protocol described by Griffies et al. (2012)). A common atmospheric state helps to isolate model-dependent uncertainty from that induced by different atmospheric states. Second, all participating models are global ocean-ice models, which have been used in different coupled climate models. Many of these climate models have participated in the Climate Model Intercomparison Project (CMIP). Model (in)consistency diagnosed from these ocean-ice models can provide information not only to Arctic researchers, but also to climate model developers for improving their Arctic Ocean components. Third, model intercomparisons for different topics and regions of the world ocean are done in parallel under the CORE-II framework (see other papers in this special issue). The combination of these studies will provide an overall view on the current status of global ocean-ice models used in climate research. We hope that the joint efforts can provide information useful to improve overall climate model integrity.

Our focus in the CORE-II Arctic framework is on the Arctic sea ice extent and 
concentration, the solid and liquid FW budget, and the Arctic intermediate water layer. We discuss which characteristics are more consistently simulated in the models and what common issues exist among them. Comparisons are made to available observations. We will compare and discuss the simulated properties, but their impact on the large scale circulation is beyond the scope of this work. We try to present the model intercomparison with a broad view including the three major Arctic topics mentioned above. This is in line with the pedagogic aspect of the CORE project. In order to maintain the readability we split the large content into three papers. This paper deals with Arctic sea ice extent and solid freshwater. The other two papers focus on the Arctic liquid freshwater (Wang et al., 2015) and the hydrography in the Arctic Ocean (Ilicak et al., 2015) respectively.

\subsection{Participating models}

Data from fourteen CORE-II models are analyzed in this paper. Thirteen of them ¿were described in the first CORE-II paper focused on the North Atlantic Danabasoglu et al. 2014)1. One new model is the global $0.25^{\circ}$ MOM. Adding it to the analysis serves to provide information on how fine horizontal grid spacing can influence simulation results. The models are listed in Table 1, together with the groups names operating the models and the basic model configuration information. Seven different sea ice models are used in the fourteen ocean-ice models (see Appendix A for descriptions of the sea ice models). Most of the models use z-level (or $z^{*}$ ) coordinates, except for three models with isopycnal or hybrid vertical grids (GOLD, FSU and Bergen). One model is an unstructured-mesh model (AWI-FESOM), configured with traditional climate model resolution for the purpose of the CORE-II project. Among the participating models, ten models have nominal $1^{\circ}$ horizontal resolution, three with $0.5^{\circ}$, and one with $0.25^{\circ}$. The resolution in $\mathrm{km}$ varies significantly in space and direction in the Arctic Ocean, so we can only give very approx-

\footnotetext{
${ }^{1}$ The analysis done for this paper discovered a bug in the CERFACS NEMO model. The NEMO grid is folded at the North Pole for an entire grid line going from Canada to Asia at $78^{\circ} \mathrm{W}$. On this specific grid line, the wind forcing fields need to be rotated onto the local grid coordinates. This is not correctly done in the CERFACS simulation, leading to spurious signals in ice dynamical fields (e.g., as shown by the sea ice concentration in Figure 4. It is found that this bug has a very local imprint and did not significantly influence the freshwater budget analyzed in this work.
} 
Table 1: Summary of the ocean and sea-ice models in alphabetical order according to the participating group name (first column). The table includes the name of the combined ocean-sea ice configuration (if any); the ocean model name and its version; the sea-ice model name and its version; vertical coordinate and number of layers/levels in parentheses; orientation of the horizontal grid with respect to the North Pole/Arctic; the number of horizontal grid cells (longitude, latitude); and the horizontal resolution (longitude, latitude). In MRI-A and MRI-F, the vertical levels shallower than $32 \mathrm{~m}$ follow the surface topography as in sigma-coordinate models. In AWI-FESOM, the total number of surface nodes is given, because it has an unstructured grid. The suite of participating models include 13 models analyzed in the CORE-II North Atlantic paper (Danabasoglu et al., 2014), and one $0.25^{\circ}$ fine horizontal grid spacing model (MOM0.25). FSU-HYCOM has a new model version for the CORE-II study (Danabasoglu et al. 2015), but it is not included in this work.

\begin{tabular}{|c|c|c|c|c|c|c|c|}
\hline Group & Configuration & Ocean model & Sea-ice model & Vertical & Orientation & Horiz. grid & Horiz. res. \\
\hline AWI & & FESOM 1.4 & FESIM 2 & z (46) & Displaced & 126000 & Nominal $1^{\circ}$ \\
\hline Bergen & NorESM-O & MICOM & CICE 4 & $\sigma_{2}(51+2)$ & Tripolar & $360 \times 384$ & Nominal $1^{\circ}$ \\
\hline CERFACS & ORCA1 & NEMO 3.2 & LIM 2 & $\mathrm{z}(42)$ & Tripolar & $360 \times 290$ & Nominal $1^{\circ}$ \\
\hline $\mathrm{CMCC}$ & ORCA1 & NEMO 3.3 & CICE 4 & z (46) & Tripolar & $360 \times 290$ & Nominal $1^{\circ}$ \\
\hline CNRM & ORCA1 & NEMO 3.2 & Gelato 5 & $\mathrm{z}(42)$ & Tripolar & $360 \times 290$ & Nominal $1^{\circ}$ \\
\hline FSU & & HYCOM 2.2 & CSIM 5 & hybrid (32) & Displaced & $320 \times 384$ & Nominal $1^{\circ}$ \\
\hline GFDL-MOM & ESM2M-ocean-ice & MOM 4p1 & SIS1 & $\mathrm{z}^{*}(50)$ & Tripolar & $360 \times 200$ & Nominal $1^{\circ}$ \\
\hline GFDL-UNSW & MOM0.25 & MOM 5 & SIS1 & $\mathrm{z}^{*}(50)$ & Tripolar & $1440 \times 1070$ & Nominal $0.25^{\circ}$ \\
\hline GFDL-GOLD & ESM2G-ocean-ice & GOLD & SIS1 & $\sigma_{2}(59+4)$ & Tripolar & $360 \times 210$ & Nominal $1^{\circ}$ \\
\hline Kiel & ORCA05 & NEMO 3.1 .1 & LIM 2 & z $(46)$ & Tripolar & $722 \times 511$ & Nominal $0.5^{\circ}$ \\
\hline MRI-A & MRI assimilation & MOVE/MRI.COM 3 & MK89; CICE & $\mathrm{z}(50)$ & Tripolar & $360 \times 364$ & $1^{\mathrm{o}} \times 0.5^{\mathrm{o}}$ \\
\hline MRI-F & MRI free run & MRI.COM 3 & MK89; CICE & $\mathrm{z}(50)$ & Tripolar & $360 \times 364$ & $1^{\circ} \times 0.5^{\circ}$ \\
\hline NCAR & & POP 2 & CICE 4 & $\mathrm{z}(60)$ & Displaced & $320 \times 384$ & Nominal $1^{\circ}$ \\
\hline NOC & ORCA1 & NEMO 3.4 & LIM 2 & $\mathrm{z}(75)$ & Tripolar & $360 \times 290$ & Nominal $1^{\circ}$ \\
\hline
\end{tabular}


imate mean values. MOM0.25 has about $12 \mathrm{~km}$ horizontal resolution, Kiel-ORCA05 and FESOM have about $24 \mathrm{~km}$, and the other models have about $48 \mathrm{~km}$.

One of the participating models, MRI-A, is a global ocean data assimilation system. It is the same as MRI-F except that temperature and salinity observational data are assimilated into the model. It was run for 70 years starting from model year 231 of the MRI-F integration. The first 10 years are treated as a spin-up phase and the last 60 years (associated with the period of CORE-II forcing) are used in this work. Its results are compared to other models to provide information on whether the assimilation improves the key diagnostics of the Arctic Ocean. However, we do not include it for calculating model ensemble means.

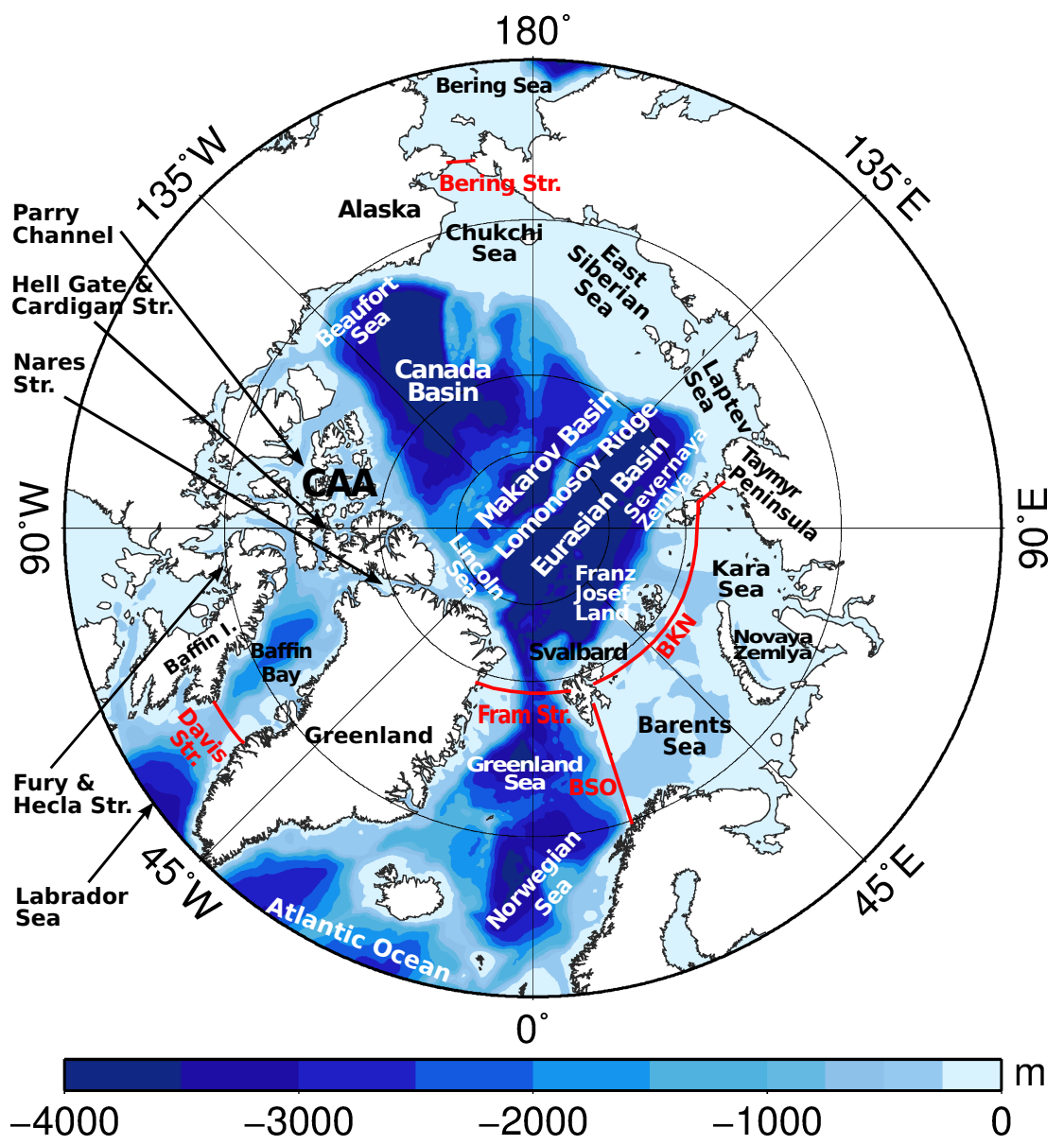

Figure 1: Arctic Ocean bottom topography [m]. The Arctic gateways discussed in the paper are shown with red lines. BSO stands for southern Barents Sea Opening, BKN for Barents/Kara Seas northern boundary, and CAA for Canadian Arctic Archipelago.

In this paper we define the Arctic Ocean domain with the following four gateways: 
Bering Strait, Fram Strait, Davis Strait, and the Barents and Kara Seas northern boundary (BKN) (see Figure 1). Bering Strait is the only gateway connecting the Arctic Ocean with the Pacific. In the Atlantic sector, the Arctic Ocean is connected with the Nordic Seas via Fram Strait, with the Labrador Sea via Davis Strait, and with the Barents/Kara Seas then the Nordic Seas via the BKN. We take Davis Strait rather than the Canadian Arctic Archipelago (CAA) as one of the Arctic Ocean boundaries for simplicity because the number of CAA passages connecting the Arctic Ocean and Baffin Bay is different among the models.

Table 1 shows the basic model configurations, therein we list the models in the alphabetical order with respect to the names of the contributing groups. In all figures and other tables in this paper, we will group the models according to types of vertical coordinates and model origins, when possible. The five models based on NEMO are put closer, the same for the two MOM models with different horizontal resolution, the three isopycnal (and hybrid) models, and the free-run and assimilated MRI models.

\subsection{Basic concepts}

Sea ice extent. The decline of Arctic sea ice, with possible impact on different components of the Earth System (Bhatt et al. 2014), has emerged as a leading signal of global warming. The mean state and decline of sea ice need to be quantified, often by using the so-called sea ice extent, which is defined as the sum of ice covered areas with sea ice concentrations of at least $15 \%$. The sea ice concentration is the fractional area of the ocean covered by sea ice.

Sea ice area, the summed product of the ice concentration and area of each data element within the ice extent, is another widely used quantity for describing sea ice cover. In this work we only assess the simulated sea ice extent, and note that the descending trends of Arctic sea ice extent and area are different, especially when compared for particular regions and seasons (Cavalieri and Parkinson, 2012; Comiso, 2012).

For evaluating the sea ice extent, we compare both the simulated mean state and trend with satellite observations (Fetterer et al., 2002). The comparison is made for September and March when the Northern Hemisphere (NH) sea ice extent has minimum and maximum, respectively (note that the maximal and minimal descending trends are in 
September and May, respectively, for the period of 1979 - 2010 Cavalieri and Parkinson, 2012)). In addition to the total NH sea ice extent, we also evaluate the models for one chosen region, the Barents Sea, where most significant sea ice retreat is predicted in simulations of future climate (Koenigk et al., 2013).

AArctic freshwater. The Arctic Ocean is a big FW reservoir (Serreze et al., 2006; Dickson et al., 2007). It receives FW as river runoff, precipitation and inflow from Bering Sea. The amount of FW stored in the Arctic Ocean is an important index that can be used to describe the climate status of the Arctic Ocean. The excess FW received by the Arctic Ocean is finally released to the North Atlantic through Fram and Davis Straits. Due to the proximity to the deep water formation sites and potential impact on large scale pcean circulation (Dickson et al., 1988; Goosse et al., 1997; Hakkinen, 2002; Wadley and Bigg, 2002), the FW flux from the Arctic Ocean to the North Atlantic is one of the key variables describing the linkage between the Arctic and subpolar regions.

FW in the Arctic Ocean exists in the solid form mainly as sea ice and in the liquid form mainly located in the upper ocean. We call sea ice and particular ocean waters $F W$ because their salinity is lower than a reference value, which is chosen according to the context of discussed topics. For example, if one wants to study the impact of Arctic FW export on the deep water formation in the North Atlantic, she/he will take the mean salinity of the subpolar North Atlantic as the reference salinity; if one analyzes the FW budget in the Arctic Ocean, she/he might choose a value representing the mean state of the Arctic Ocean. In this paper we focus on the Arctic region, so we take 34.8, a value close to the mean salinity in the Arctic basins as the reference salinity following Aagaard and Carmack (1989) and Serreze et al. (2006). Using this common value allows us to compare the model results directly with the synthesized Arctic FW budget (Serreze et al., 2006; Haine et al., 2015) and analyses in many observational and model studies ${ }^{2}$.

Understanding the Arctic FW budget involves quantifying both the Arctic FW storage and sources, including fluxes through the gateways. The FW storage in the Arctic Ocean

\footnotetext{
${ }^{2}$ Note that slightly different reference salinity values have also been used in literature. See the comments on the choice of reference values and the definition of FW by Bacon et al. (2015) and Carmack et al. (2015).
} 
can be quantified using the so-called freshwater content (FWC), which is the amount of zero-salinity water required to be taken out from the ocean (or sea ice) so that the ocean (or sea ice) salinity is changed to the chosen reference salinity. The FW flux through a gateway is similarly defined as the equivalent flux of zero-salinity water. See Appendix B for how the FWC and FW fluxes are calculated. When we evaluate the Arctic FW storage and sources, we will focus on three aspects: mean state, interannual changes and seasonal variability, and the model ensemble means are also assessed at the end.

\subsection{Model spin-up}

The CORE-II atmospheric state used to the drive the models covers 60 years from 1948 to 2007 (Large and Yeager, 2009). All models are run for 300 years, corresponding to 5 consecutive loops of the 60-year forcing period following the CORE-II protocol (Griffies et al. 2012). The first 4 loops are considered as model spin-up and the model intercomparisons use the 5th loop. Because the Arctic sea ice retreats in the recent decades and each model loop starts from the end of the preceding loop, the simulated Arctic Ocean experiences vigorous adjustment at the beginning of each loop. For example, the low sea ice extent and thickness at the end of 2007 increases after the atmospheric state is changed back to 1948 in the next model loop. When discussing the model results, we only take the last 30 model years of the 5th model loop, if not otherwise mentioned.

Only using the last 30 years helps to reduce the influence of the loop to loop adjustment on our analysis, although this choice is somewhat arbitrary as we do not know exactly how long the adjustment can affect the ocean-ice system. Observations available for model evaluation are concentrated in the period of the last three decades, which is another reason for us to focus on this period. Although our discussion focuses on the last 30 years, in most of the plots of time series in this paper we show the whole 5 th loop because the information can be useful for readers who are interested in a longer time period.

The paper is organized as follows. First we discuss sea ice extent and concentration in Section 2, then the solid FW budget is assessed in Section 3. The concluding remarks are given in Section 4. 


\section{Sea ice extent and concentration} qvation period is characterized by a significant decline of the Arctic sea ice cover Parkinson et al., 1999; Serreze et al., 2007; Comiso and Nishio, 2008; Parkinson and Cavalieri, 2008). The sea ice retreat continued to accelerate in the recent decade, the most strongly in September (Stroeve et al., 2012b; Cavalieri and Parkinson, 2012; Comiso, 2012). A few

\footnotetext{
${ }^{3}$ So far the lowest Arctic sea ice extent was observed in September 2012, beyond the period of model integration.
} 

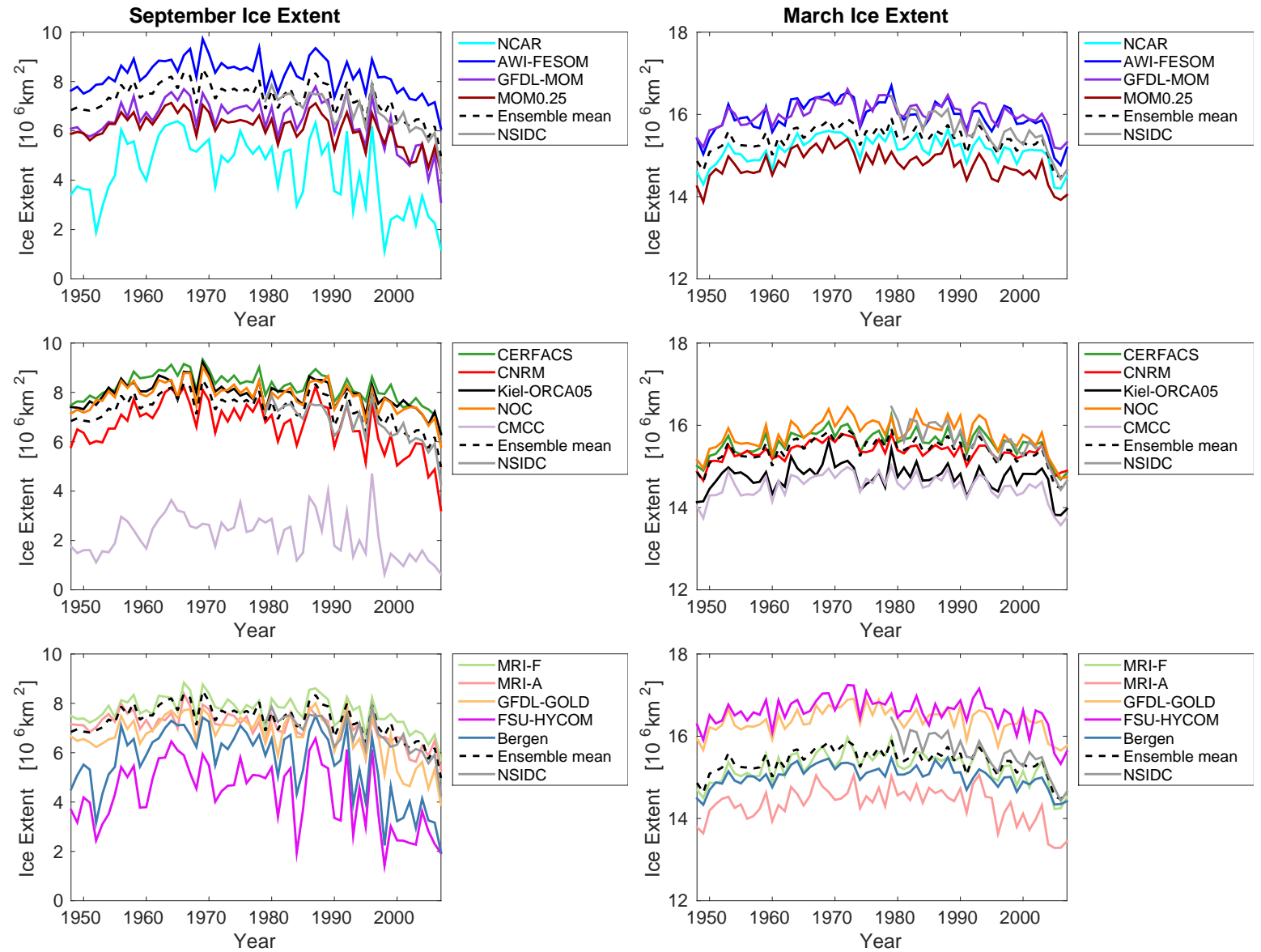

Figure 2: Northern Hemisphere (left) September and (right) March sea ice extent $\left[10^{6} \mathrm{~km}^{2}\right]$ in the last model loop. Note that the assimilation model MRI-A is not used in the calculation of the model ensemble mean. The observation from NSIDC (Fetterer et al. 2002) is shown with gray lines for the period of 1979-2007. 
We define the model spread as the standard deviation of the mean sea ice extent. The model spread in September is about $26 \%$ of the observed mean sea ice extent, much larger than the spread in March (see Table 2). The growth of sea ice extent in freezing seasons is confined by the continents around the Arctic Ocean, which can partly explain the smaller model spread in March. The September sea ice extent is overestimated in five models (AWI-FESOM, CERFACS, Kiel-ORCA05, NOC and MRI-F), and significantly underestimated in four models (NCAR, CMCC, FSU-HYCOM, Bergen). In the latter four models, the September sea ice extent drops to anomalously low levels already at the end of the 1990s. Except for these four models, all other models produced lowest September sea ice extent in 2007 in the model integration period, in agreement with the observation.

Table 2: Northern Hemisphere (NH) sea ice extent: mean, standard deviation (STD), correlation with observation, linear trend, and the 2007 value. The last two columns show the model ensemble mean and spread. ${ }^{1}$

\begin{tabular}{|c|c|c|c|c|c|c|c|c|c|c|c|c|c|c|c|c|c|}
\hline & Observation & NCAR & AWI & MOM & MOM0.25 & CERFACS & CNRM & Kiel & $\mathrm{NOC}$ & CMCC & MRI-F & MRI-A & GOLD & FSU & Bergen & mean & spread \\
\hline \multicolumn{18}{|l|}{ September } \\
\hline mean & 6.95 & 3.99 & 8.18 & 6.30 & 5.96 & 8.12 & 6.46 & 7.85 & 7.76 & 2.14 & 7.65 & 6.84 & 6.52 & 4.00 & 5.27 & 6.17 & 1.87 \\
\hline STD & 0.58 & 1.44 & 0.61 & 0.89 & 0.66 & 0.42 & 0.86 & 0.43 & 0.49 & 1.04 & 0.57 & 0.61 & 0.98 & 1.54 & 1.47 & 0.88 & 0.40 \\
\hline correlation & & 0.71 & 0.76 & 0.63 & 0.73 & 0.67 & 0.67 & 0.74 & 0.64 & 0.68 & 0.79 & 0.80 & 0.62 & 0.72 & 0.60 & 0.69 & 0.06 \\
\hline trend 79-03 & -5.3 & -11.0 & -2.7 & -6.4 & -4.4 & -2.5 & -5.9 & -2.1 & -2.6 & -5.2 & -3.5 & -4.2 & -7.5 & -10.9 & -12.8 & -6.0 & 3.6 \\
\hline trend $79-07$ & -7.2 & -11.3 & -4.9 & -8.9 & -5.5 & -4.3 & -8.5 & -3.9 & -4.5 & -6.0 & -5.4 & -4.9 & -9.0 & -10.4 & -13.6 & -7.2 & 3.0 \\
\hline 2007 ice extent & 4.30 & 1.21 & 6.09 & 3.12 & 4.31 & 6.34 & 3.23 & 6.31 & 5.80 & 0.64 & 5.69 & 5.26 & 3.89 & 1.93 & 1.98 & 3.89 & 2.04 \\
\hline \multicolumn{18}{|l|}{ March } \\
\hline mean & 15.72 & 15.20 & 15.98 & 16.06 & 14.78 & 15.66 & 15.38 & 14.78 & 15.87 & 14.57 & 15.33 & 14.43 & 16.40 & 16.60 & 15.06 & 15.51 & 0.64 \\
\hline STD & 0.34 & 0.22 & 0.25 & 0.22 & 0.24 & 0.21 & 0.15 & 0.24 & 0.28 & 0.20 & 0.29 & 0.38 & 0.24 & 0.29 & 0.21 & 0.24 & 0.04 \\
\hline correlation & & 0.65 & 0.66 & 0.60 & 0.76 & 0.59 & 0.76 & 0.65 & 0.46 & 0.80 & 0.45 & 0.37 & 0.68 & 0.21 & 0.67 & 0.61 & 0.16 \\
\hline trend $79-03$ & -3.4 & -1.4 & -1.3 & -1.1 & -1.6 & -1.3 & -0.7 & -0.9 & -1.8 & -1.2 & -2.1 & -3.3 & -0.9 & -1.3 & -1.7 & -1.3 & 0.4 \\
\hline trend $79-07$ & -4.7 & -2.7 & -3.1 & -2.5 & -2.8 & -2.7 & -1.7 & -2.3 & -3.5 & -2.7 & -3.5 & -4.8 & -2.2 & -3.1 & -2.6 & -2.9 & 0.7 \\
\hline 2007 ice extent & 14.65 & 14.50 & 15.19 & 15.32 & 14.04 & 14.85 & 14.90 & 13.97 & 14.74 & 13.77 & 14.52 & 13.45 & 15.77 & 15.63 & 14.42 & 14.74 & 0.62 \\
\hline
\end{tabular}

\subsection{Variability and trend}

The strength of interannual variability, represented by the standard deviation of monthly time series, is stronger in September than in March in the observation and the models (Table 2). In September, the models with lower sea ice extent tend to have stronger interannual variability; the four models with extremely low sea ice extent have the strongest variability as also shown in Figure 2 (NCAR, CMCC, FSU-HYCOM, 

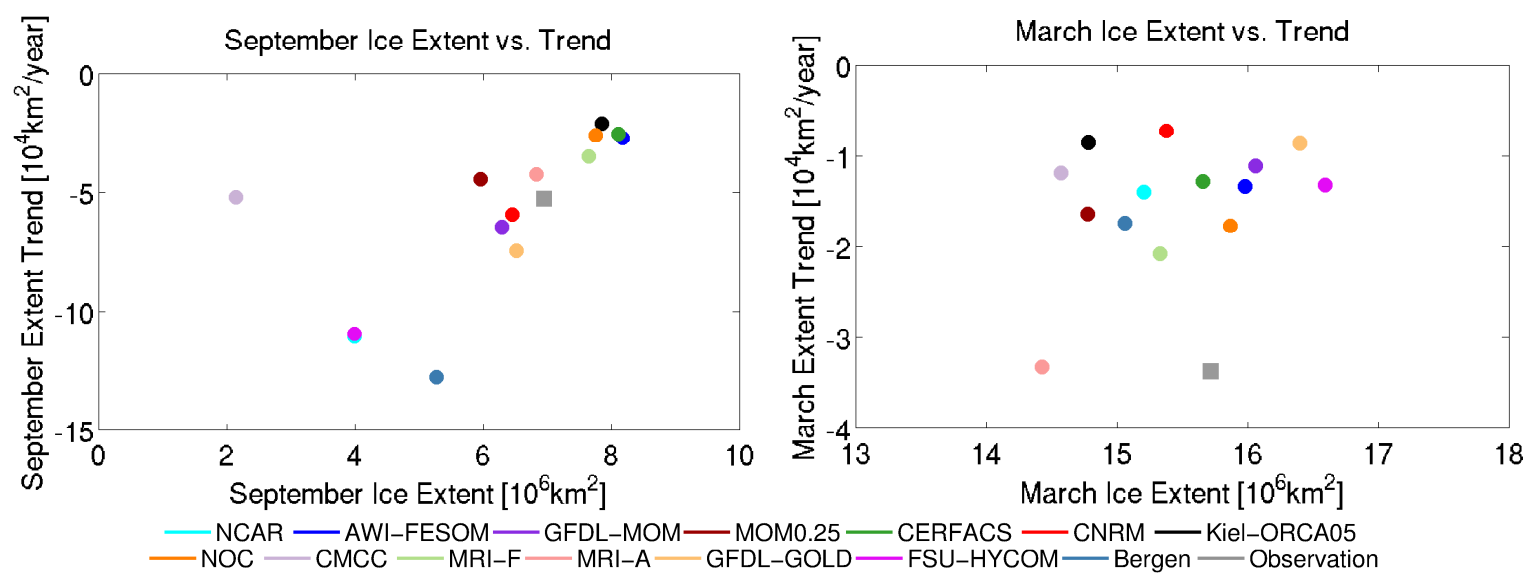

Figure 3: Northern Hemisphere $(\mathrm{NH})$ sea ice extent $\left[10^{6} \mathrm{~km}^{2}\right]$ versus its trend $\left[10^{4} \mathrm{~km}^{2} /\right.$ year$]$. Observations are shown with gray squares. The period $1979-2003$ is used in the calculation. Note that the $\mathrm{y}$-axis scales are different in the two panels.

Bergen). The correlation between observed and modelled sea ice extent is moderately high for September, ranging from 0.6 to 0.8, and it is also rather good for most of the models in March (except for FSU-HYCOM, MRI-A, MRI-F and NOC).

The NH sea ice extent has a descending trend in both September and March according to the satellite observation (Figure 2). The linear trends calculated for two periods (1979 - 2003 and 1979 - 2007) are shown in Table 2. The second period contains the last few years when the trend tends to accelerate. In the following we will first discuss the simulated sea ice extent trend, and then compare the September sea ice concentration in 2007, the year when a low sea ice extent event was observed.

All the models show downward trends in both months, consistent to the observation. The sea ice extent drops faster in September than in March, which is reproduced by the models. However, the spread in the simulated trend is large, particularly in September. NCAR, FSU-HYCOM and Bergen exhibit descending trends more than twice the observed one in September for the period 1979 - 2003. They are among those that significantly underestimate the September sea ice extent. Kiel-ORCA05, CERFACS, NOC and AWI-FESOM have less than half of the observed descending trend in September for this period. They are among the models that overestimate the sea ice extent. Therefore, the descending trend in sea ice extent roughly anti-correlates with the sea ice extent in September: models that overestimate the sea ice extent, tend to underestimate the de- 
scending trend, and vice versa (see Figure 3). The relationship between September sea ice extent and its trend can be explained by the fact that both of them can be influenced by sea ice thickness (see discussion in Section 3.1.2). The CMCC result is an exception in that it has very low sea ice extent for the whole integration period and has a low descending trend.

The descending trend of sea ice extent in March is underestimated in all the models except for MRI-A (Figure 3). The ensemble mean sea ice extent in March is lower than the observation in the 1980s, although it is very close to the observation afterwards (Figure2). This causes the simulated mean trend in March to be only about one third of the observed trend for the period 1979 - 2003. Therefore, in order to improve the representation of March sea ice extent trend, the winter sea ice extent in the colder years (the 1980s) needs to be tuned higher in terms of the model ensemble mean. Because the model ensemble mean better represents the observed March sea ice extent in more recent years, the trend calculated using the whole period (1979 - 2007) compares with the observation better than considering the shorter period (1979 - 2003, Table 2). Further analysis shows that the underestimation of sea ice extent trend in March can be attributed to underestimated trends in sea ice concentration along ice edges on both the Atlantic and Pacific sides (in Labrador, Greenland, Barents and Okhotsk Seas, not shown).

A pronounced September sea ice extent minimum was observed in 2007 (Stroeve et al. 2008 ). Six models produced larger September sea ice extent than the observation in this year (AWI-FESOM, CERFACS, Kiel-ORCA05, NOC, MRI-F and MRI-A), and the aforementioned four models with low September sea ice extent in the whole period of the last decade have significantly lower value also in this year (Table 2). The 2D distribution of sea ice concentration in September 2007 is compared to the observation in Figure 4. Five models have sea ice only along the northern boundary of the CAA, missing the observed sea ice in the central Arctic and the ice tongue towards the Laptev Sea. In the other nine models, the observed sea ice retreat toward the North Pole from the Siberian side is reproduced, but most of these models show a weaker decline. GFDLMOM and GFDL-GOLD have ice edges close to the observation in the western Arctic, but they have too low ice concentration near the North Pole. On the contrary, MOM0.25 and NOC have too high sea ice concentration. All the models tend to have more summer 

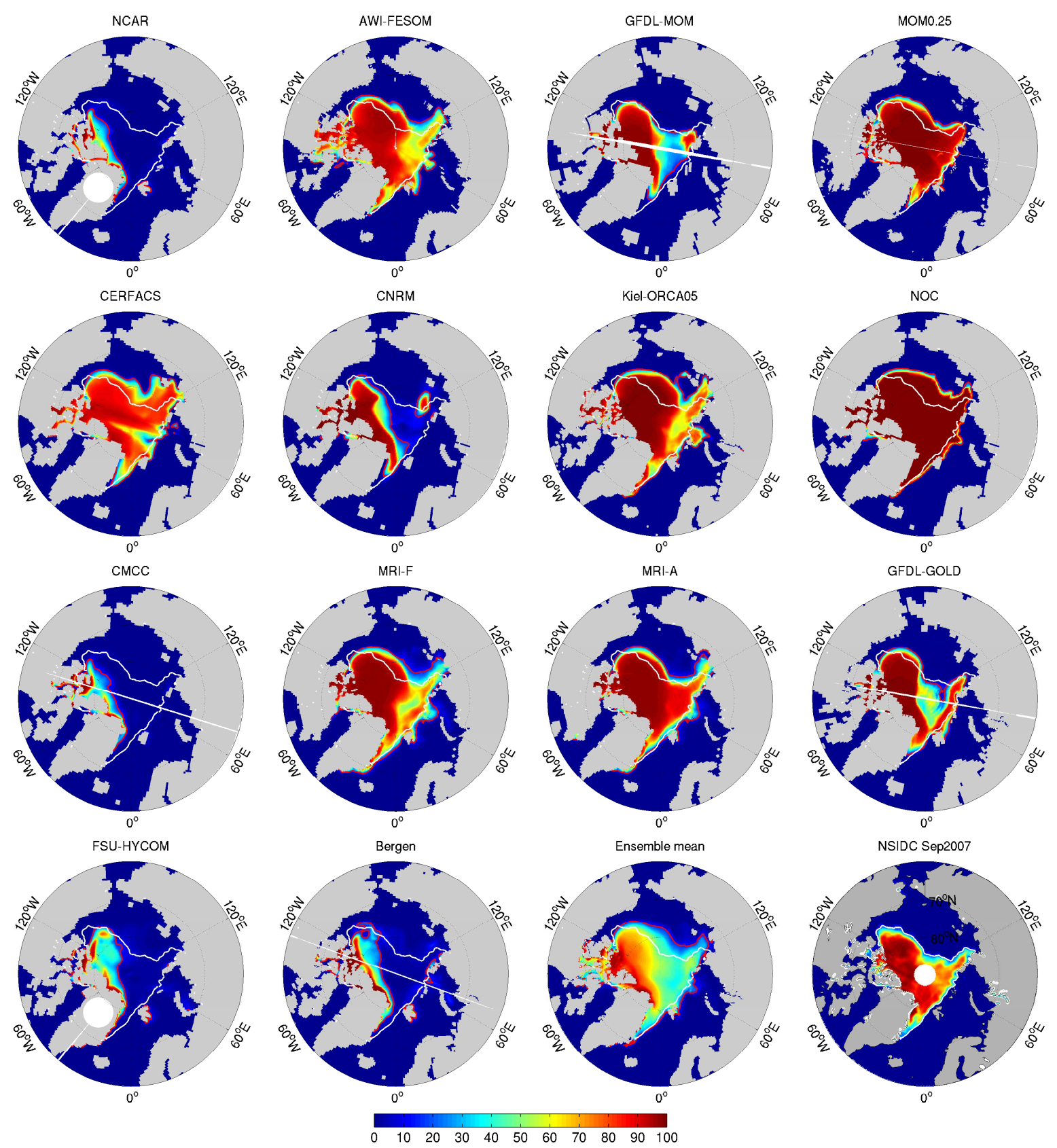

Figure 4: Observed and simulated sea ice concentration [\%] for September 2007. The last panel is the satellite observation from NSIDC (Fetterer et al., 2002). The NSIDC $15 \%$ ice concentration contour line is shown in white; The simulated $15 \%$ ice concentration contour line is shown in red. 

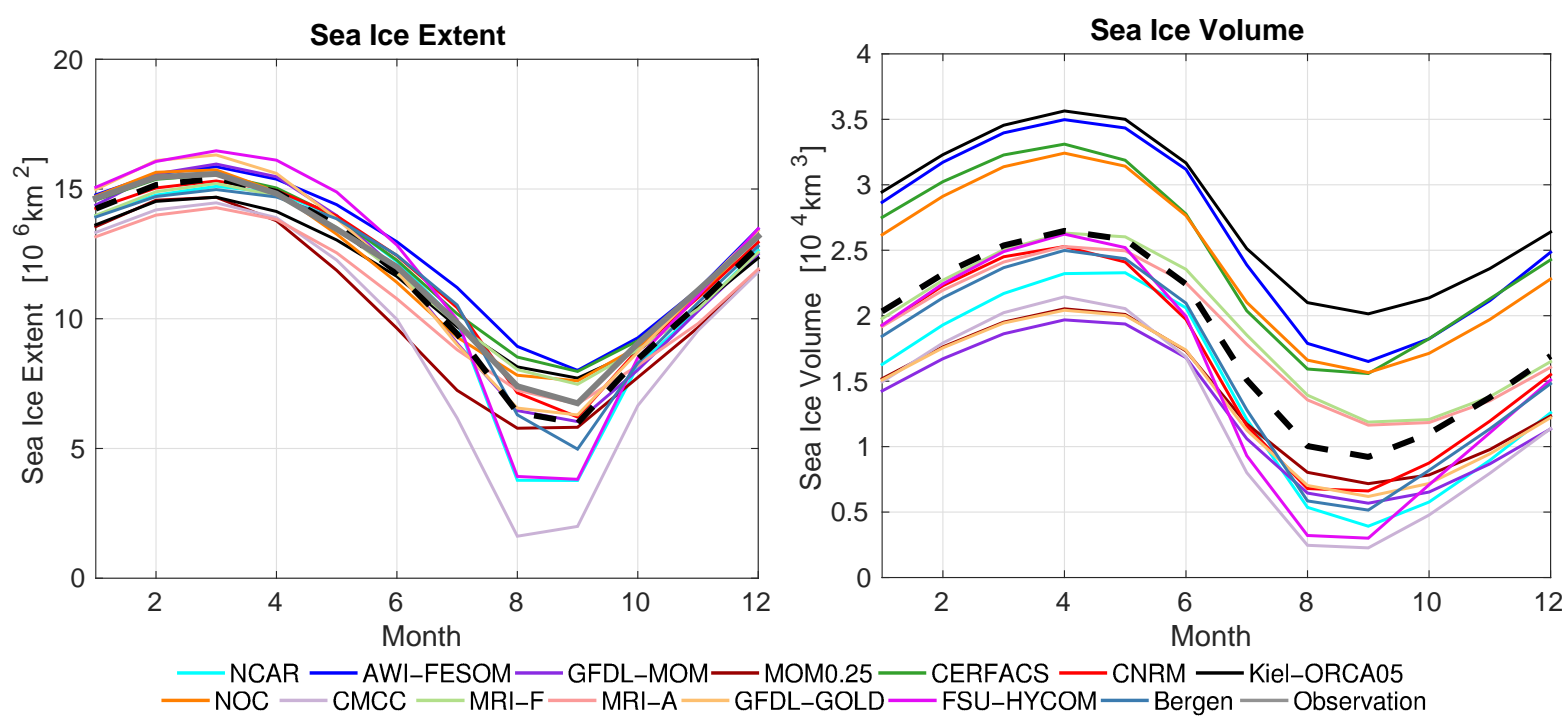

Figure 5: Seasonal cycle of Northern Hemisphere (left) sea ice extent $\left[10^{6} \mathrm{~km}^{2}\right]$ and (right) sea ice volume $\left[10^{4} \mathrm{~km}^{3}\right]$ averaged over the years 1979 - 2007. The model ensemble means are shown with dashed lines. The gray line in the left panel shows the observed sea ice extent (Fetterer et al., 2002).

sea ice in the southern CAA than the observationt It was found that the downward shortwave radiation in the CORE normal year forcing has a negative bias, which can lead to overestimation of summer sea ice in the CAA (Wang et al., 2012). It is not clear if a similar bias exits in the CORE interannual forcing.

On the seasonal scale, all the models have maximal sea ice extent in March, and nine models have the minimum in September, in agreement with observations (left panel of Figure 5). CMCC, NCAR, FSU-HYCOM and MOM0.25 have similar or even smaller sea ice extent in August than in September, different from the observed seasonality. The model spread in winter can be partly attributed to the difference in model ocean area, for example, in the CAA region, which is very differently represented by the models.

\subsection{Sea ice extent in Barents Sea}

The Barents Sea connects the Nordic Seas and the Arctic Ocean, and it is one of the two major pathways for Atlantic Water to enter the Arctic Ocean. Most of the oceanic heat that passes the Barents Sea Opening (BSO) is released to the atmosphere within the

\footnotetext{
${ }^{4}$ Note that the observed sea ice concentration has larger uncertainty in summer than in winter. And ice can be falsely detected along coasts due to contamination by signals from land; this may reduce the accuracy of the observation in the CAA region.
} 

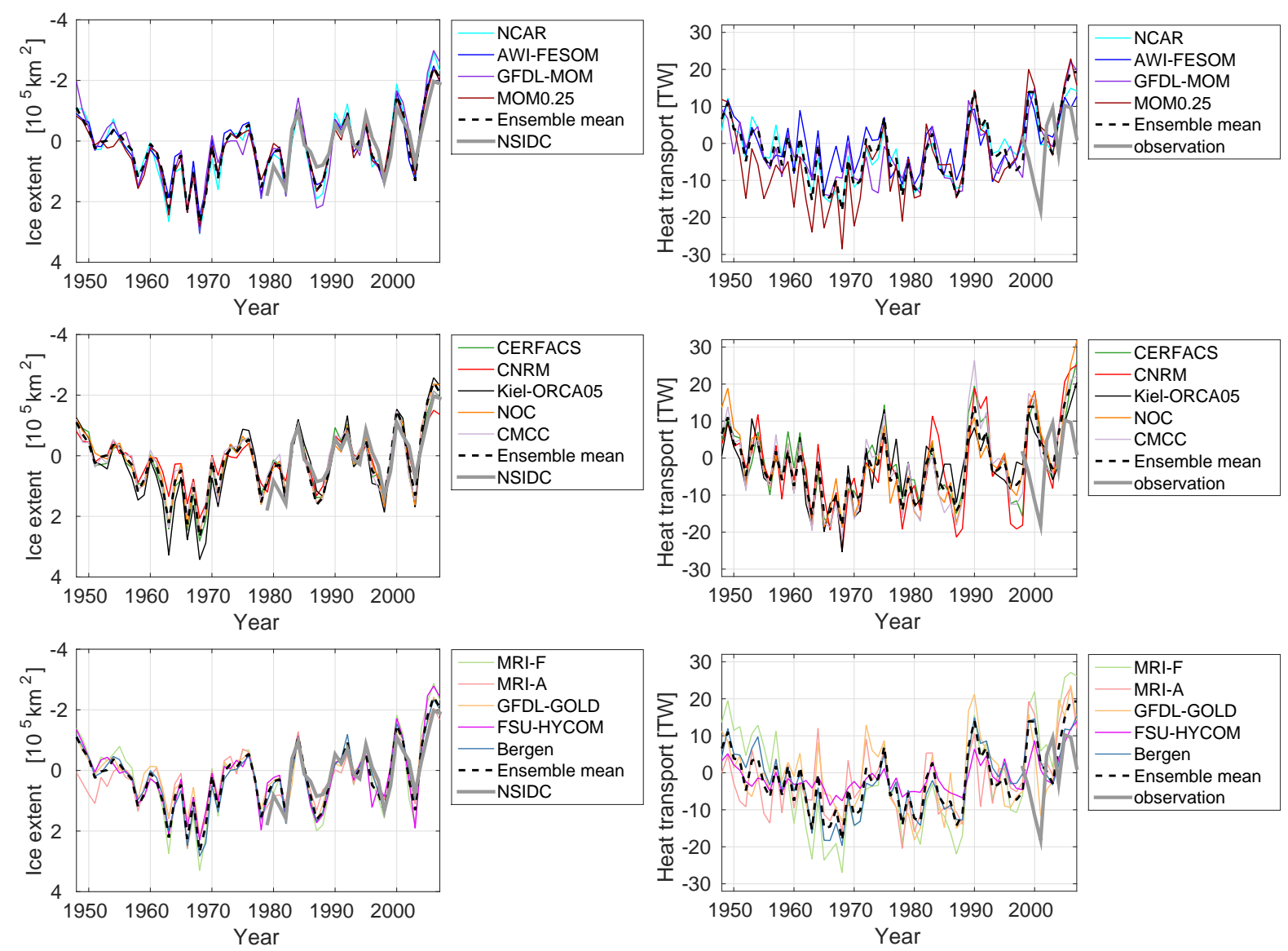

Figure 6: Anomaly of annual mean (left) Barents Sea sea ice extent and (right) BSO heat transport (referenced to $0^{\circ} \mathrm{C}$ ) in the last model loop. Observations (sea ice extent after Fetterer et al. (2002) and BSO heat transport after Smedsrud et al. (2013)) are shown with thick gray lines. Note that the vertical axes of sea ice extent are inverted. 
Barents Sea, so it is the most active region of air-sea heat exchange in the Arctic Ocean (Smedsrud et al., 2013). Sea ice extent in the Barents Sea has large interannual variability and it has a descending trend in recent years as shown by observations (Arthun et al. (2012), see Figure 6(left)). The most significant Arctic sea ice retreat is found in Barents Sea in simulations of future climate (Koenigk et al., 2013). Therefore, it is interesting to see how well sea ice in the Barents Sea is represented in the models.

All the models well reproduced the observed sea ice extent variability in the Barents Sea as shown by the anomaly of annual mean sea ice extent (Figure6(left)).$^{5}$ The simulated sea ice extent is anti-correlated with the heat transport (referenced to $0^{\circ} \mathrm{C}$ ) through the BSO in all the models, with heat transport leading 0-1 year (Table 3). This supports the idea that the heat transport through the BSO drives the interannual variability of Barents Sea sea ice extent suggested by Arthun et al. (2012). The interannual variability of BSO heat transport agrees well among the models, but the discrepancy to the observed heat flux is surprisingly high (Figure6(right)). As shown by Arthun et al. (2012), the low spatial resolution of moorings can potentially produce large uncertainty in the observed heat flux, which might explain the difference between the observation and models.

Although the variability of sea ice extent in the Barents Sea is well reproduced, most of the models did not adequately simulate the mean values (Table 3). The bias of simulated mean sea ice extent cannot simply be explained by the simulated BSO heat transport: the highest heat flux is in MOM0.25, while the lowest sea ice extent is in CNRM. Overall, the interannual variation of the Barents Sea sea ice extent, including the magnitude of the variability, is a robust feature that is well represented in all the models, despite the spread in the simulated mean sea ice extent and mean heat transport.

\subsection{Summary on the model ensemble mean of sea ice extent}

In this section we summarize the simulated Northern Hemisphere (NH) sea ice extent based on the model ensemble mean. Other remarks will be given in the concluding section (Section 4).

\footnotetext{
${ }^{5}$ The anomaly is calculated by removing the temporal mean from the time series. The same for the anomalies in other figures.
} 
Table 3: The Barents Sea sea ice extent, BSO heat transport, correlation coefficients between the annual mean Barents Sea sea ice extent and BSO heat transport at both 0 and 1 (heat fluxes lead) year lag. Positive heat transport indicates flux into the Barents Sea. The last 30 model years $(1978-2007)$ are used in the analysis. ${ }^{1}$

\begin{tabular}{|c|c|c|c|c|c|c|c|c|c|c|c|c|c|c|c|c|c|}
\hline & Observation & NCAR & AWI & MOM & MOM0.25 & CERFACS & CNRM & Kiel & $\mathrm{NOC}$ & $\mathrm{CMCC}$ & MRI-F & MRI-A & GOLD & FSU & Bergen & mean & spread \\
\hline ice extent & $3.6^{a}$ & 5.4 & 4.9 & 5.1 & 4.4 & 3.7 & 2.7 & 4.0 & 5.0 & 5.3 & 4.4 & 3.3 & 5.0 & 5.7 & 4.3 & 4.5 & 0.8 \\
\hline heat flux & $70 \pm 5^{b}$ & 37.6 & 61.1 & 42.9 & 87.8 & 45.0 & 55.8 & 58.9 & 66.1 & 78.2 & 65.3 & 66.0 & 69.4 & 11.3 & 51.7 & 56.2 & 19.5 \\
\hline correlation 0 & & -0.77 & -0.57 & -0.74 & -0.67 & -0.80 & -0.89 & -0.61 & -0.73 & -0.72 & -0.77 & -0.68 & -0.53 & -0.85 & -0.72 & -0.72 & 0.10 \\
\hline correlation 1 & & -0.79 & -0.71 & -0.85 & -0.70 & -0.68 & -0.82 & -0.61 & -0.69 & -0.74 & -0.74 & -0.76 & -0.74 & -0.70 & -0.74 & -0.73 & 0.06 \\
\hline
\end{tabular}

${ }^{1}$ Sea ice extent is shown in $10^{5} \mathrm{~km}^{2}$, and heat transport in TW. Heat transport is referenced to $0^{\circ} \mathrm{C}$. All correlations are significant at the $95 \%$ confidence level. Observational data reference: (a) Fetterer et al. 2002], (b) Smedsrud et al. 2013]. Missing values are shown with N/A, the same in other tables.
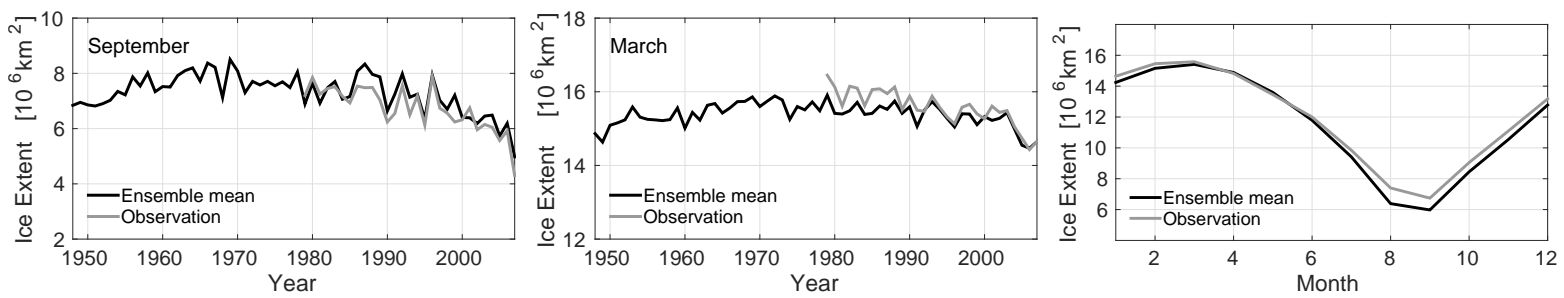

Figure 7: Model ensemble mean of the Northern Hemisphere sea ice extent for (left) September, (middle) March, and (right) the mean seasonal cycle. The observations from NSIDC are shown with gray curves.

- The mean sea ice extent in September is $6.17 \times 10^{6} \mathrm{~km}^{2}$ averaged over the period of 1979 - 2003, smaller than the observation $\left(6.95 \times 10^{6} \mathrm{~km}^{2}\right)$ by about $11 \%$ (Table 2). The mean sea ice extent in March is closer to the observation than in September.

- In September the descending trend of NH sea ice extent is relatively well captured $\left(-6.0 \times 10^{4} \mathrm{~km}^{2} /\right.$ year compared to the observed trend of $-5.3 \times 10^{4} \mathrm{~km}^{2} /$ year for the period of 1979 - 2003, Table 2). The models underestimate the sea ice retreat rate in March because they produce lower ice extent than the observation in the 1980s (Figure 7).

- Most of the observed high and low sea ice extent events are reproduced by the model ensemble mean (Figure 7). The mean correlation coefficients for the simulated and observed ice extent are 0.69 and 0.61 for September and March, respectively.

- The seasonal cycle of NH sea ice extent is well represented by the model ensemble mean. The models on average tend to have a stronger seasonal cycle with lower sea ice extent than the observation in summer. 


\section{Solid freshwater}

Freshwater (FW) in the Arctic Ocean exists in the solid form mainly as sea ice and 3.2 and 3.3 , respectively. A summary on the model ensemble mean of solid FW budget is given in Section 3.4

\subsection{Mean state}

\subsubsection{Solid freshwater sources} that is, the solid FW fluxes through the Arctic gateways and the sea ice thermodynamic growth rate. Table 4 shows the mean values of these diagnostics. In all the models 
solid FW fluxes through the gateways are the largest at Fram Strait. However, the solid FW fluxes have a big range among the models. At Fram Strait, the spread in the simulated solid FW flux is $810 \mathrm{~km}^{3} /$ year, about one third of the synthesized mean value $\left(-2300 \pm 340 \mathrm{~km}^{3} /\right.$ year, Serreze et al. (2006)). Four models obtained Fram Strait solid FW fluxes within the uncertainty range of the synthesized value, including CERFACS, NOC, MRI-A and Bergen. Solid FW transport contains contributions from both sea ice and snow fluxes. It is found that the Fram Strait sea ice and snow fluxes are well correlated in terms of interannual variability, and that sea ice flux is the major contributor to the mean solid FW transport (accounting for more than $90 \%$ on average).

Table 4: Arctic Ocean solid freshwater (FW) source terms and solid freshwater content (FWC) relative to salinity 34.8 . The last 30 years $(1978-2007)$ are used in the analysis. ${ }^{1}$

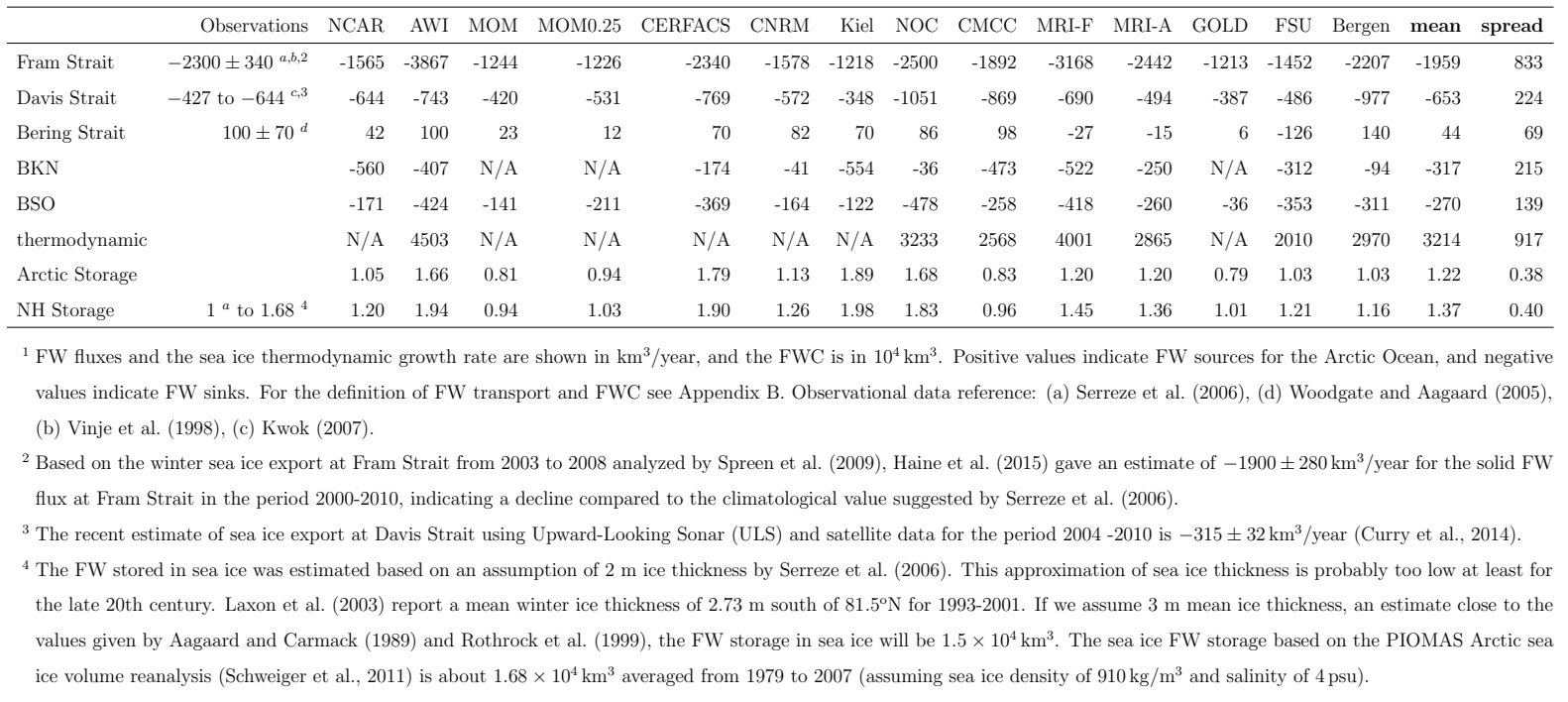

Sea ice FW flux depends on both sea ice thickness and drift velocity (see Appendix B for the definition of sea ice FW flux). Kiel-ORCA05 is one of the models with the thickest sea ice, but it has very low Fram Strait solid FW export; The Bergen model has too thin sea ice compared to the observation, but its Fram Strait solid FW export is close to the observed value. This indicates that the fidelity of simulated sea ice flux does not reflect the model skills in representing sea ice thickness and velocity. We will assess the Arctic sea ice thickness in Section 3.1.2.

The observed net solid FW flux at Davis Strait is toward the Labrador Sea (Kwok, 390 2007; Curry et al., 2014), and this direction is reproduced in all the models (Table 4). The largest export flux is found in NOC and Bergen, with about twice the observed value. 
A small amount of solid FW is imported to the Arctic Ocean through Bering Strait according to observations (Woodgate and Aagaard, 2005), but three models obtained (small) export fluxes, including MRI-F, MRI-A and Bergen $\sqrt{6}$

The models agree that Arctic sea ice is exported at the BKN when averaged over the last 30 years, and the Barents Sea has net sea ice export through the BSO. In some models the amount of solid FW flux entering Barents/Kara Seas from the north is very similar to that leaving at the BSO, while some models have distinguishable difference between the two fluxes. NCAR, CERFACS, CNRM and Kiel-ORCA05 have larger fluxes at the BKN, but NOC and Bergen have larger outflow at the BSO. This means that there is no agreement in the models on whether the Barents/Kara Seas are a region of sink or source for sea ice.

The Arctic sea ice thermodynamic growth rate is provided by a few model groups. From these data we can conclude that the spread in sea ice production in the Arctic Ocean is the largest in the solid FW source terms (Table 4).

\subsubsection{Solid freshwater content}

Sea ice volume, thus the freshwater stored in sea ice, depends on the sea ice thickness. Before discussing the sea ice volume, we first evaluate the modelled sea ice thickness by comparing with observations. Sea ice thickness observations from submarines, moorings, field measurements and satellites are not continuous and very limited in space and time. The sea ice thickness fields derived from the ICEsat satellite are available for a few months in spring and fall each year starting from 2003 (Kwok et al., 2009). For the purpose of model evaluation, we calculated the mean values for spring (Feb., Mar. and April) $2004-$ 2007 for each model, and defined the observational field by averaging all available ICEsat data in spring $2004-2007$ (Figure 8).

The observed sea ice has larger thickness towards the CAA, and smaller thickness towards the Siberian coast. All models can reproduce this feature, but the simulated sea

6 The sea ice transport at Bering Strait is very small compared to other Arctic gateways, so the model bias at this gateway has small impact on the total Arctic FW budget. In this paper we show the results for all major Arctic gateways for completeness. Quantifying impacts of model biases and their significance is not pursued. 

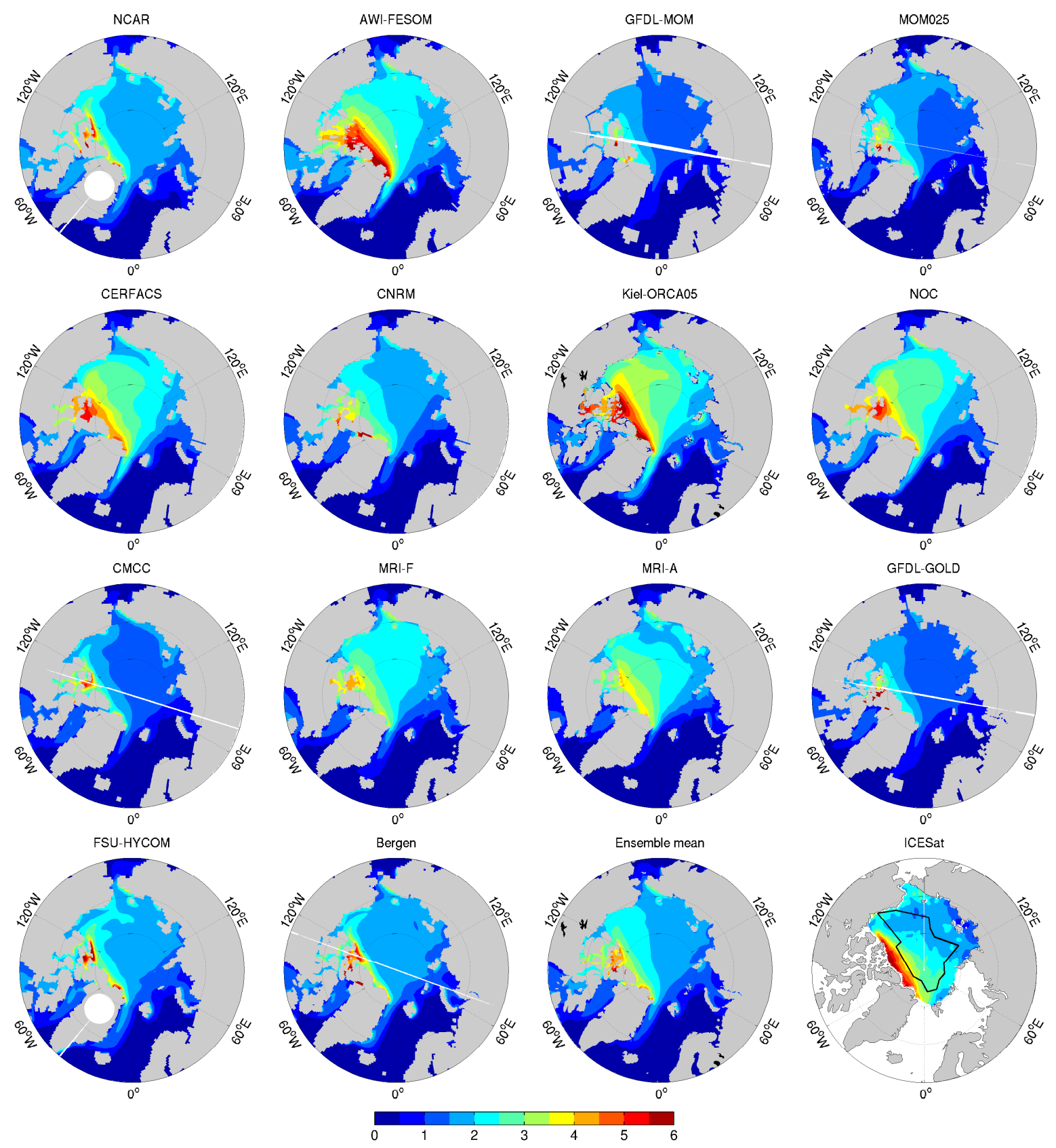

Figure 8: Observed and simulated spring sea ice thickness [m]. The last panel is the ICEsat observation (Kwok et al., 2009). The model results are the mean values for spring (Feb., Mar. and April) 2004 2007 of the last model loop. The observation is the average over all available ICEsat data in spring 2004 - 2007. The black polygon in the last panel indicates the region of the SCICEX box. 
ice thickness differs from the observation significantly. This is also seen in the AOMIP models (Jahn et al. 2012a). The sea ice thickness along the northern coast of CAA is best simulated by AWI-FESOM and Kiel-ORCA05, but they tend to have thicker sea ice than the observation towards the Siberian coast. CERFACS, NOC, MRI-F and MRIA underestimate the sea ice thickness towards the CAA and overestimate the sea ice thickness towards the Siberian coast. Other models underestimate the sea ice thickness in most of the regions where satellite observations are available.

The five models which have too high September sea ice extent with low descending trend (AWI-FESOM, CERFACS, Kiel-ORCA05, NOC and MRI-F, see Figure 3), overestimate sea ice thickness in spring for the considered period (Figure 8). The three models with too low September sea ice extent and high descending trend (NCAR, FSU-HYCOM and Bergen), underestimate sea ice thickness. If the simulated sea ice in late winter and spring is too thick, more heat is needed to melt it to produce open ocean area in the melting season. Therefore, overestimated sea ice thickness could lead to too high sea ice extent in summer and underestimation of its trend. However, a few models with similar spring sea ice thickness turned out to have very different September sea ice extent, so model details need to be carefully examined in order to understand individual model behaviour and to improve sea ice thickness, concentration and their trend simultaneously.

After comparing the sea ice thickness, we focus on the sea ice FW storage in the following. The models show a spread of $0.41 \times 10^{4} \mathrm{~km}^{3}$ in the sea ice FWC, about one third of the model mean value (Table 4). Due to lacking long term sea ice thickness observations, there are only rough estimates for the solid FWC in literature. Serreze et al. 440 (2006) give an estimate of $10^{4} \mathrm{~km}^{3}$ by assuming $2 \mathrm{~m}$ sea ice thickness. If we assume $3 \mathrm{~m}$ mean ice thickness, a value more representative for the sea ice state in the past few decades Aagaard and Carmack, 1989; Rothrock et al., 1999), the FWC is $1.5 \times 10^{4} \mathrm{~km}^{3}$. The FW stored in sea ice based on the PIOMAS Arctic sea ice volume reanalysis (Schweiger et al., 2011) is about $1.68 \times 10^{4} \mathrm{~km}^{3}$ averaged from 1979 to 2007 (assuming sea ice density of $910 \mathrm{~kg} / \mathrm{m}^{3}$ and salinity of $4 \mathrm{ppt}$ ). The model ensemble mean of the NH solid FWC is $1.37 \times 10^{4} \mathrm{~km}^{3}$, within the range of different estimates mentioned above.

The model spread in sea ice volume can be attributed to the spread in sea ice thickness and extent. In September, the sea ice volume tends to be higher in models with larger 

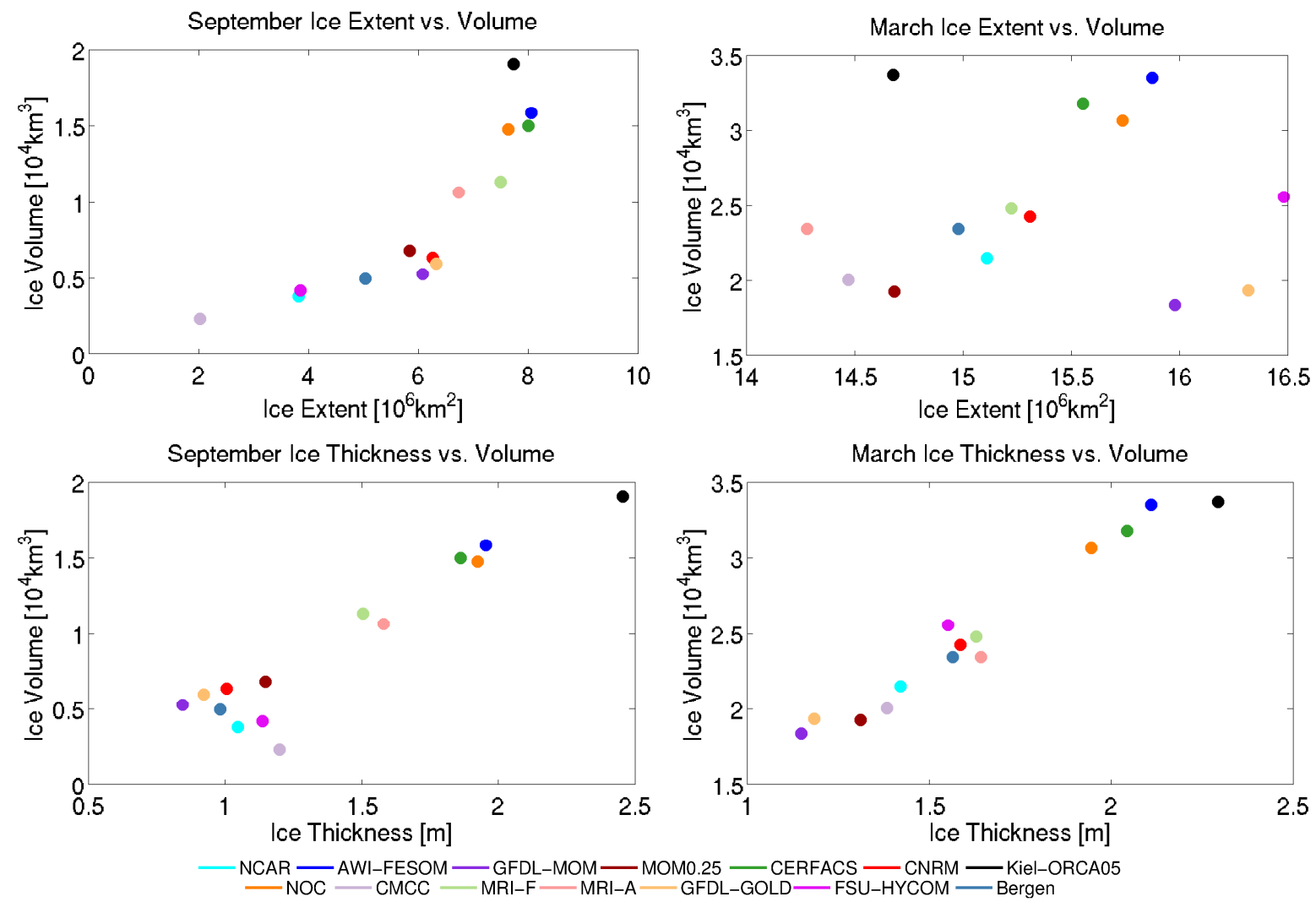

Figure 9: (upper) The relationship between Arctic sea ice volume $\left[10^{4} \mathrm{~km}^{3}\right]$ and extent $\left[10^{6} \mathrm{~km}^{2}\right]$. (lower) The relationship between Arctic sea ice volume and thickness [m]. The last 30 model years $(1978-2007)$ are used in the analysis. 
sea ice extent, and vice versa, but this relationship is not found in March (Figure 9). The growth of Arctic sea ice extent is constrained by the surrounding continents when thickness and volume still increase in the freezing season. This can explain the weaker connection between sea ice extent and volume in March. Models with large ice volume tend to have thick sea ice in both September and March. Although the sea ice volume correlates with sea ice extent in September, the spread in sea ice volume is mainly caused by the difference in sea ice thickness (except for the four models with too low ice extent: CMCC, NCAR, FSU-HYCOM and Bergen). This is because the range of September sea ice extent among the models is about $6-8 \times 10^{6} \mathrm{~km}^{2}$, while the highest sea ice thickness is about 3 times the lowest $(0.8-2.4 \mathrm{~m})$. The four models that have largest sea ice volume (Kiel-ORCA05, CERFACS, NOC and AWI-FESOM, see Table 4) have thicker sea ice than the other models (Figure 8).

\subsection{Interannual variability and trend}

In this section we first discuss the statistics of the annual mean solid FW budget. Then the interannual variability of solid FW transport through each Arctic gateway is examined in Section 3.2.1. The variation of solid FWC in the Arctic Ocean is analyzed in Section 3.2.2, where the focus is on (a) the relationship between sea ice volume and thickness and (b) the sources of sea ice volume changes.

Table 5: Standard deviation of the Arctic Ocean solid freshwater (FW) fluxes and solid freshwater content (FWC) for the last 30 model years $(1978-2007)$. It is calculated using annual mean time series. ${ }^{1}$

\begin{tabular}{|c|c|c|c|c|c|c|c|c|c|c|c|c|c|c|c|c|c|}
\hline & Observations & NCAR & AWI & MOM & MOM0.25 & CERFACS & CNRM & Kiel & NOC & $\mathrm{CMCC}$ & MRI-F & MRI-A & GOLD & FSU & Bergen & mean & spread \\
\hline Fram Strait & $401^{a}$ to $774^{b 2}$ & 312 & 574 & 246 & 275 & 429 & 295 & 295 & 511 & 333 & 596 & 580 & 229 & 231 & 453 & 367 & 130 \\
\hline Davis Strait & & 34 & 147 & 78 & 119 & 162 & 94 & 80 & 174 & 172 & 119 & 108 & 71 & 84 & 169 & 124 & 39 \\
\hline Bering Strait & & 51 & 97 & 20 & 52 & 46 & 47 & 39 & 92 & 62 & 112 & 103 & 10 & 61 & 65 & 58 & 29 \\
\hline BKN & & 302 & 588 & $\mathrm{~N} / \mathrm{A}$ & $\mathrm{N} / \mathrm{A}$ & 969 & 621 & 345 & 660 & 365 & 662 & 533 & $\mathrm{~N} / \mathrm{A}$ & 369 & 550 & 462 & 144 \\
\hline BSO & & 126 & 183 & 85 & 107 & 225 & 91 & 88 & 241 & 144 & 198 & 152 & 29 & 164 & 205 & 148 & 66 \\
\hline thermodynamic & & $\mathrm{N} / \mathrm{A}$ & 1170 & $\mathrm{~N} / \mathrm{A}$ & $\mathrm{N} / \mathrm{A}$ & $\mathrm{N} / \mathrm{A}$ & $\mathrm{N} / \mathrm{A}$ & $\mathrm{N} / \mathrm{A}$ & 1066 & 799 & 884 & 907 & N/A & 725 & 902 & 924 & 166 \\
\hline Arctic Storage & & 0.1 & 0.15 & 0.10 & 0.11 & 0.19 & 0.11 & 0.22 & 0.18 & 0.07 & 0.12 & 0.11 & 0.09 & 0.08 & 0.11 & 0.12 & 0.04 \\
\hline NH Storage & & 0.10 & 0.19 & 0.11 & 0.12 & 0.22 & 0.13 & 0.23 & 0.20 & 0.09 & 0.14 & 0.12 & 0.11 & 0.10 & 0.13 & 0.14 & 0.05 \\
\hline
\end{tabular}

${ }^{1}$ The standard deviation of FW fluxes is in $\mathrm{km}^{3} /$ year, and FWC is in $10^{4} \mathrm{~km}^{3}$. Observational data reference: (a) Kwok et al. 2004, (b) Vinje et al. 1998)

${ }^{2}$ Calculated from the annual mean data provided in the work of Kwok et al. 2004. and Vinje et al. 1998. Sea ice density of $910 \mathrm{~kg} / \mathrm{m}^{3}$ and salinity of $4 \mathrm{psu}$ are used in the calculation.

We define the strength of interannual variability using the standard deviation of the annual mean time series. The models agree that the sea ice thermodynamic growth rate has the strongest interannual variation among the solid FW source terms (see Table 5 , 


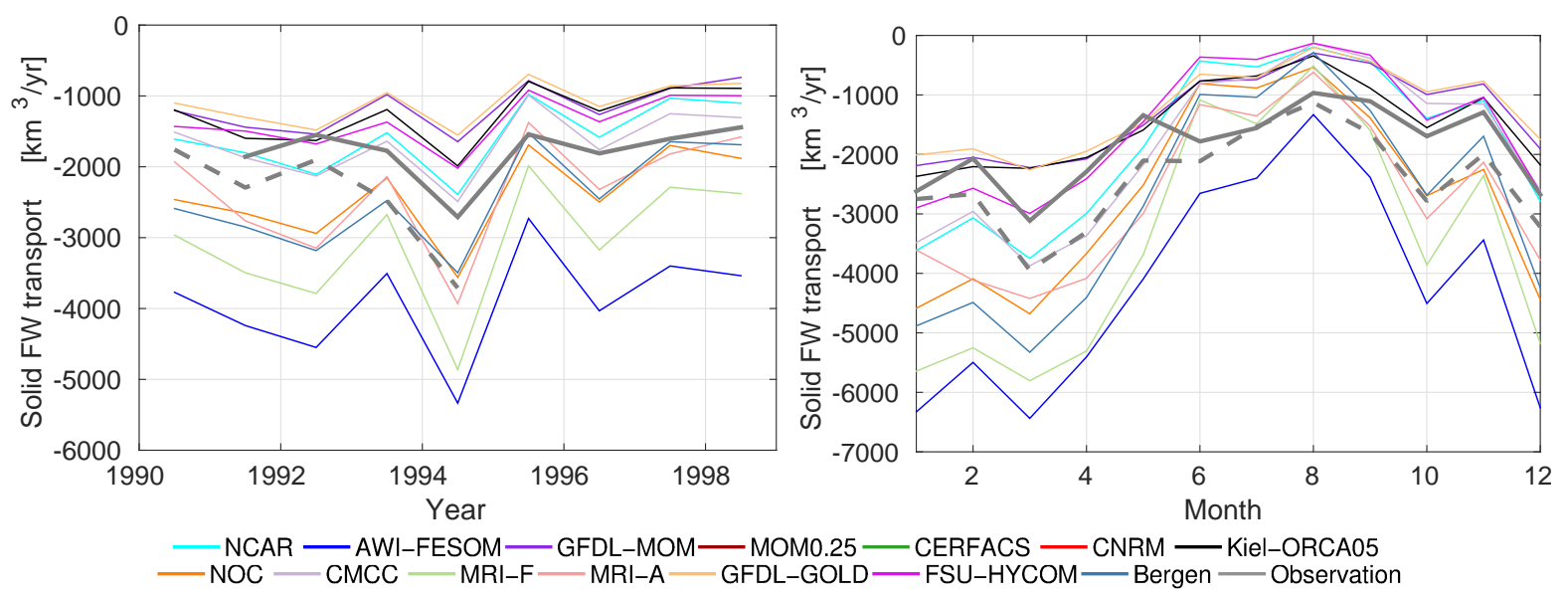

Figure 10: Fram Strait sea ice freshwater transport: (left) annual mean and (right) seasonal cycle. Observations are shown with gray thick lines: The solid lines are the estimate by Kwok and Rothrock (1999) and Kwok et al. (2004), and the dashed lines are the estimate from Vinje et al. (1998). In the left panel the winter-centered (from July to the next June) annual means are shown. A positive transport means a source for the Arctic Ocean.

and note that the thermodynamic growth rate data are available from seven models). The strongest interannual variation in lateral solid FW fluxes happens at the Fram Strait and BKN. Sea ice drift changes direction in the region of Barents/Kara Seas depending on the changes in sea level pressure patterns in that region (Kwok et al., 2005), which can lead to changes in the distribution of sea ice export through the two close gateways, thus enhancing the variability. Most models have similar variability strength at these two gateways except for CERFACS and CNRM, which have much stronger variation at the BKN. The standard deviation of the observed 5-8 years time series of sea ice export at Fram Strait is $401-774 \mathrm{~km}^{3} /$ year (based on the data provided by Vinje et al., 1998 ; Kwok and Rothrock, 1999; Kwok et al., 2004). The model results calculated from the 30 years time series tend to underestimate those observations (Table 5). However, when we calculate the modelled standard deviation over the period of the observations, the model results agree better with the observed values (not shown). At the Fram Strait and BSO, models with larger solid FW transport tend to have stronger variability; this rough relationship is not found at other gateways. 

through the Davis Strait. However, the changes throughout this period are similar to the

\footnotetext{
${ }^{7}$ Note that sea ice transport decreased again in 2009 and 2010 in the observation, which is beyond the period of model simulations.
} 


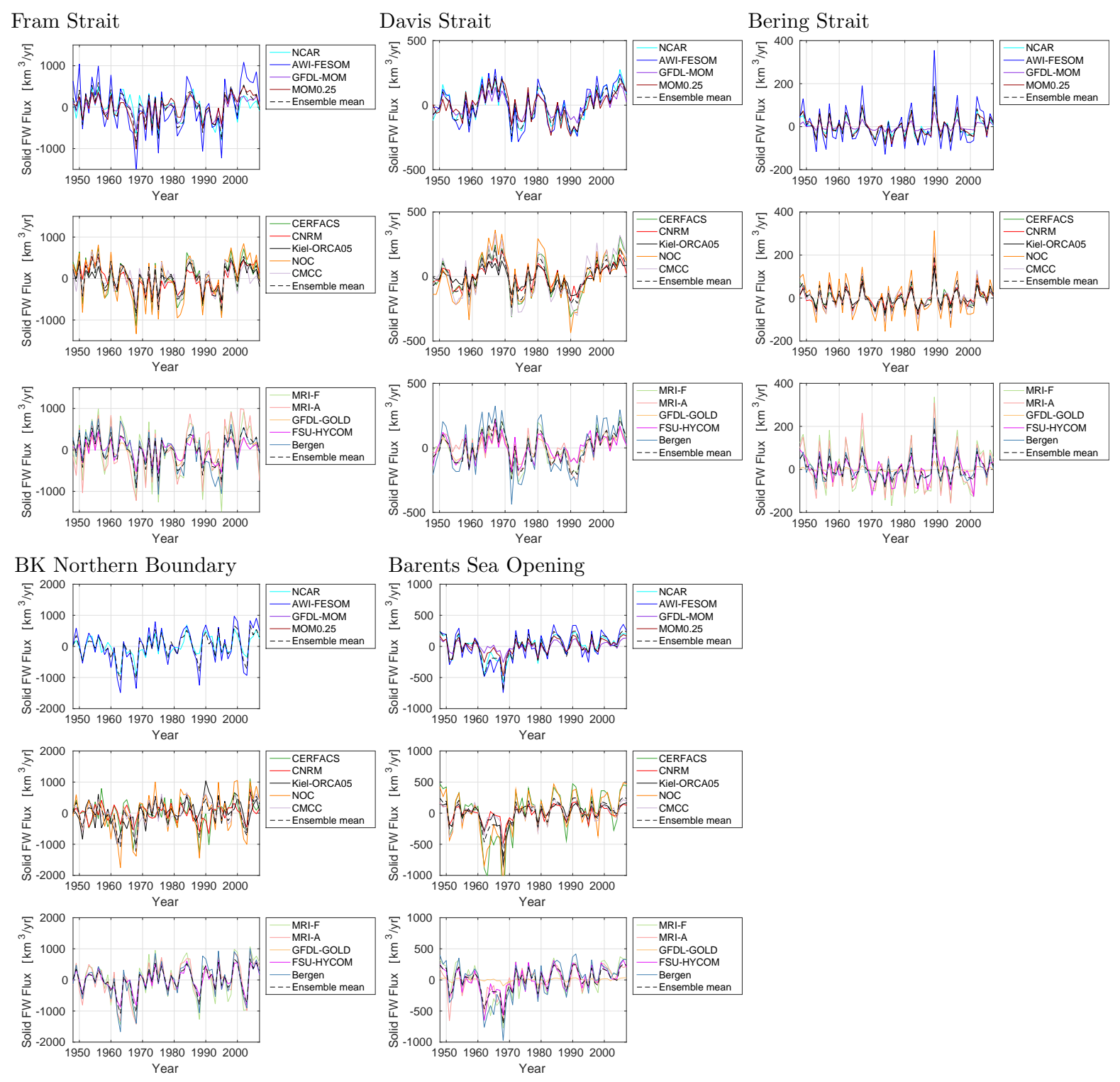

Figure 11: Anomaly of the annual mean solid freshwater transport through the Arctic gateways in the last model loop. Positive transport means a source for the Arctic Ocean. 
magnitude of decadal variability, so we cannot define the tendency in this period as a persistent trend related to climate change without considering extra information.

The correlation of annual mean solid FW fluxes between models are very high at Fram, Davis, and Bering Straits and the BSO (not shown). The good correlation between the models conforms to the consensus that sea ice drift, predominately determined by awind forcing, has large impact on sea ice volume transport variability (e.g., Kwok and Rothrock, 1999: Dickson et al., 2000; Vinje, 2001).

Sea ice thickness can also contribute to the variability of sea ice volume export (Köberle and Gerdes, 2003; Haak et al., 2003; Koenigk et al., 2006). The large sea ice export event in 1968 was preceded by a positive sea ice thickness anomaly in the Laptev Sea region in 1965/1966, which propagates towards the Canadian sector and flushes out through the Fram Strait in 1968 (Haak et al., 2003). Most of the CORE-II models show a Fram Strait sea ice thickness maximum in 1968 except for NCAR, CMCC, FSU-HYCOM and Bergen, which have highest sea ice thickness at Fram Strait in 1965 (not shown). These four models have too low sea ice thickness and summer ice extent compared to observations (Figures 2 and 8). The interpretation of the role played by Arctic sea ice thickness in these models is not robust, even though they also obtained high sea ice volume export in 1968. When we want to quantify the relative contribution of accumulated sea ice in the Arctic Ocean compared to the direct effect of enhanced sea ice drift, the models need to faithfully simulate the sea ice thickness.

No significantly high correlations between solid FW transports at different gateways are found when we consider the last 30 years or the whole 60 years. However, some pronounced events show correlation or anti-correlation between the Fram Strait and BKN sections, with agreement among the models. For example, when the BKN export increases from 1999/2000 to 2002/2003, the Fram Strait export decreases, which can be explained by the changes in sea ice drift velocity in the region of Barents/Kara Seas caused by changes in the location of local sea level pressure lows (Kwok et al., 2005). A different situation happened in 1968, when the Fram Strait and BKN have enhanced export fluxes simultaneously. The correlation between transports at the BKN and BSO is not significant (correlation coefficients less than 0.5 at $0-1$ year lag, not shown), which can be explained by the importance of thermodynamic processes within Barents/Kara 
Seas. and end of 1980s) and the fast decrease following them are consistently simulated (Figure 12 a). The interannual variability of sea ice volume can be better explained by that of sea 

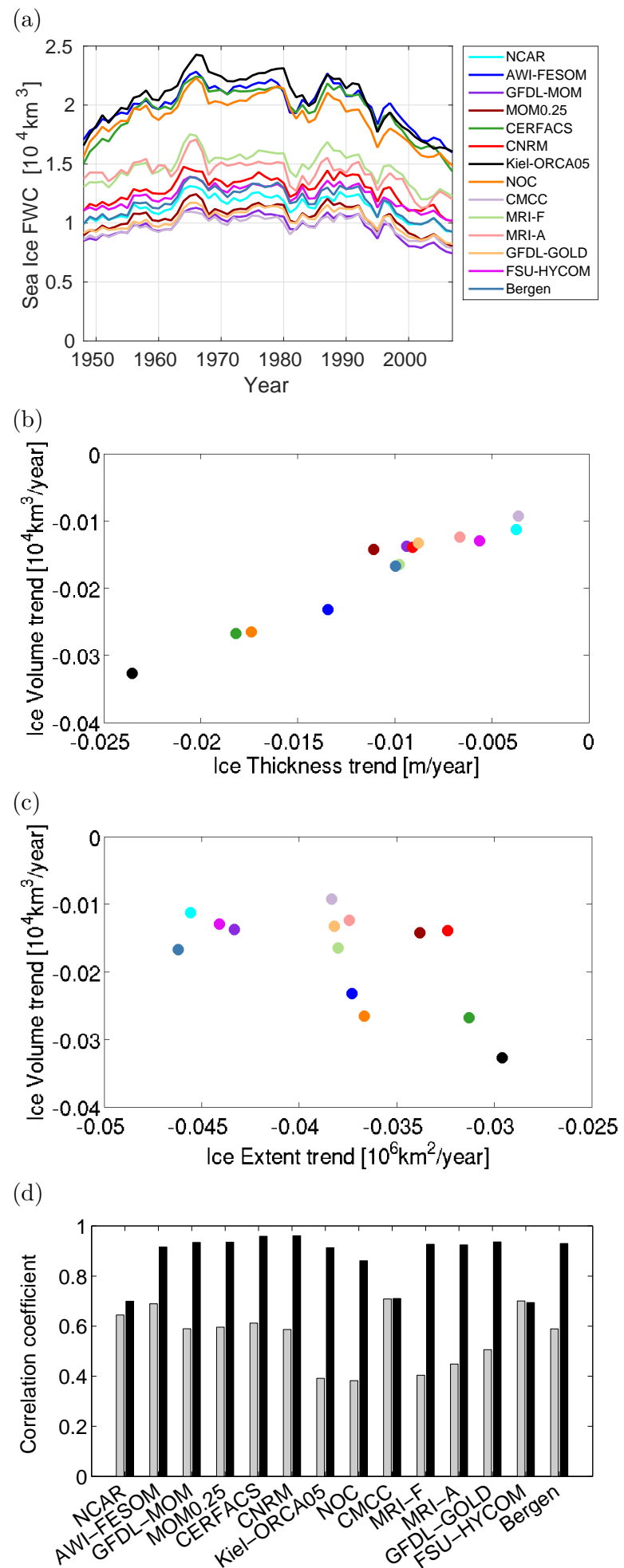

Figure 12: (a) Annual mean sea ice freshwater content $\left[10^{4} \mathrm{~km}^{3}\right]$ in the last model loop. (b) Linear trend of sea ice volume vs. that of thickness. (c) Linear trend of sea ice volume vs. that of extent. The legend for (c) and (d) is the same as in (a). (d) Correlation between sea ice volume and extent (gray), and between sea ice volume and thickness (black). The correlation coefficients are calculated using annual means after removing linear trends. The last 30 years $(1978-2007)$ are used in the calculations for $(\mathrm{b}, \mathrm{c}, \mathrm{d})$. 


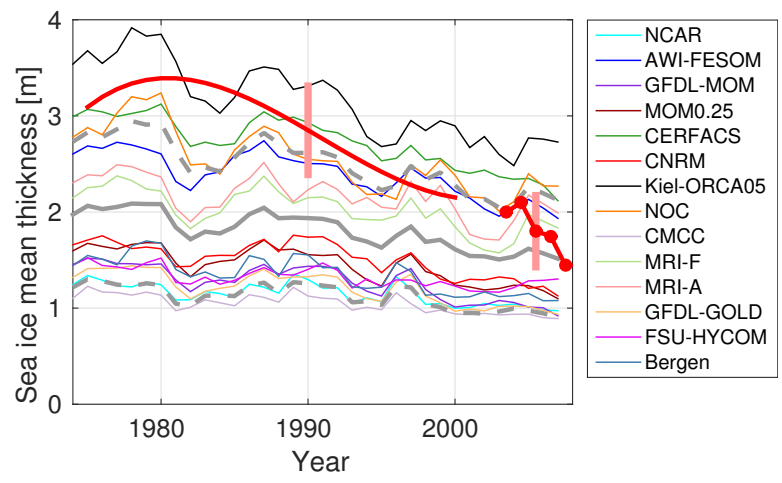

Figure 13: Simulated annual mean sea ice thickness in the SCICEX box compared with observations. The SCICEX box region is shown in the last panel of Figure 8. The model ensemble mean is shown with the thick gray line, with dashed gray lines showing plus/minus one standard deviation. The thick red solid line shows the annual mean estimate from submarine data (Rothrock et al., 2008), and the red line with circles shows ICESat data reported by Kwok and Rothrock (2009). Light red error bars show residuals in the regression of Rothrock et al. (2008) and the error estimate of ICESat data Kwok and Rothrock, 2009).

ice thickness in most of the models (Figure $12 \mathrm{~d}$ ). The correlation between sea ice volume and sea ice thickness is relatively weak only in three models that have too low sea ice thickness and extent (NCAR, CMCC and FSU-HYCOM); Bergen has also very low sea ice thickness and extent, but its sea ice volume is well correlated with sea ice thickness as in most other models.

Changes in the Arctic sea ice volume can be induced by both the thermodynamic growth rate and lateral transport through the gateways. Sea ice volume decreases in the last 30 years because the total sink is larger than the total source (Table 4), while its interannual variability is caused by the variability of both terms. Their anomalies together with the time derivative of Arctic sea ice volume are shown in Figure 14. The models agree on the interannual variability for all three time series, but the strength of variability has a range among the models. The sea ice transport and thermodynamic growth rate are sometimes out of phase. When the strong sea ice export happened in 1968, sea ice production increases and partly compensates the sea ice reduction. They can be in phase sometimes, for example at the beginning of the 1980s, both terms are in favour of reducing Arctic sea ice volume (except for CMCC which does not produce enhanced sea ice export). Although there is no persistent trend in both thermodynamic 

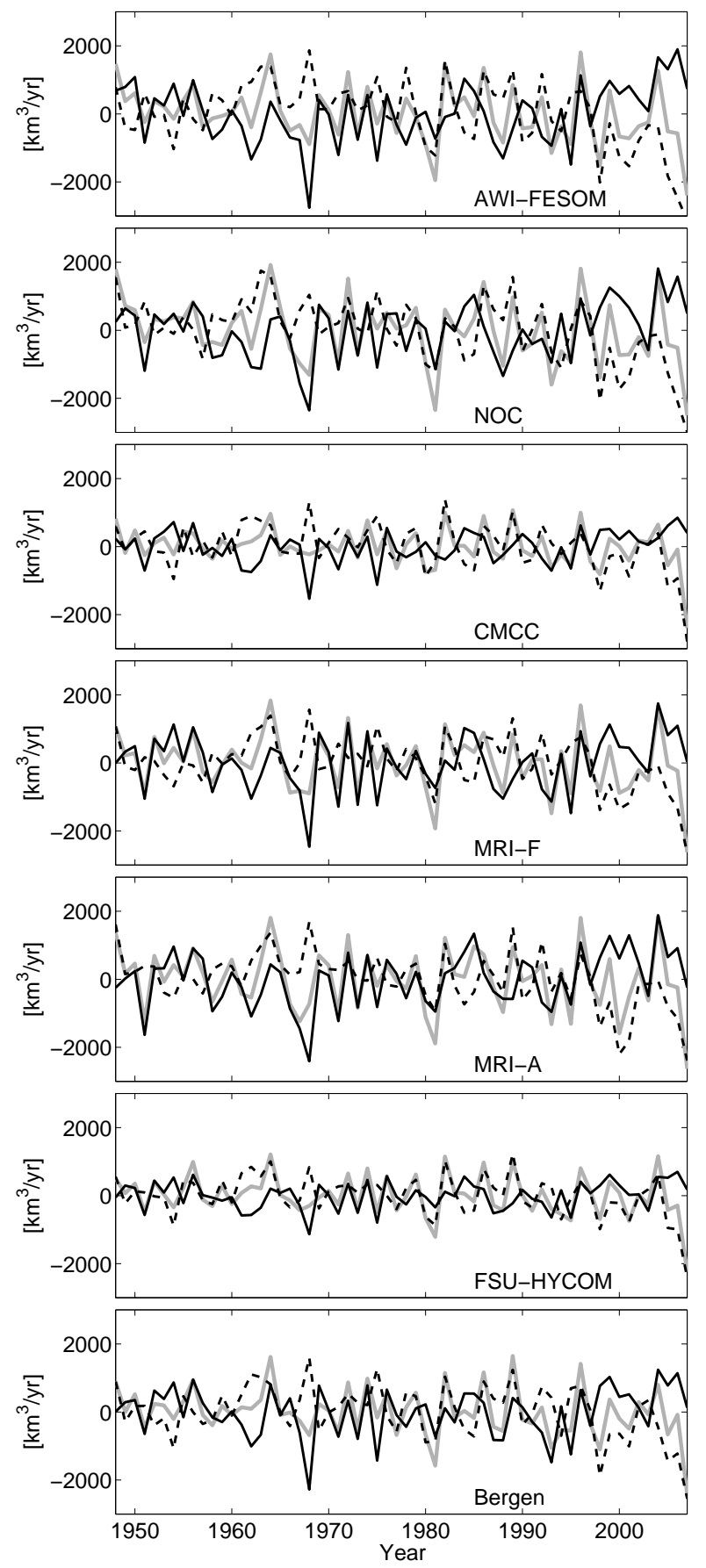

Figure 14: Anomaly of Arctic sea ice budget. The time derivative of sea ice volume is shown with gray lines; the net sea ice export flux is shown with solid black lines; and the net sea ice thermodynamic growth rate is shown with dashed black lines. Data are available from seven models. Positive values mean source for the Arctic Ocean. 
growth rates and sea ice export when the period of last 30 model years is considered, they are in a low phase in the last decade.
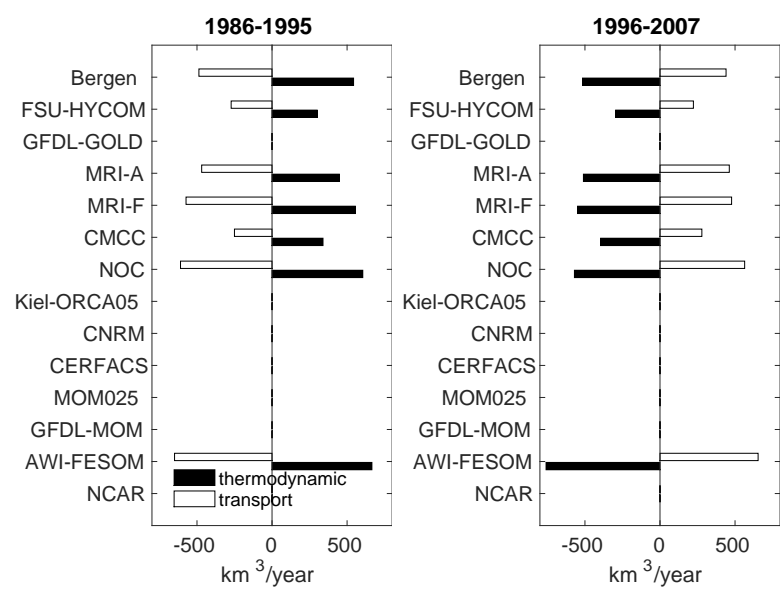

Figure 15: Sea ice sources [ $\mathrm{km}^{3} /$ year] averaged over two periods: (left) 1986 - 1995 and (right) 19962007. The anomaly from the last 30 years mean $(1978-2007)$ is shown. Both the sea ice thermodynamic growth rate and transport through the gateways are defined such that positive values refer to sources for the Arctic Ocean. Therefore, negative transport anomaly means larger export than the mean value.

To better compare the roles of two sea ice sources in the variation of sea ice volume on longer time scales, we calculated the anomaly of mean sea ice budget for two periods: $1986-1995$ and 1995 - 2007 (Figure 15). These two periods are separated by events of large drop in sea ice volume (Figure 12). In the first period the sea ice production has positive anomaly while sea ice transport has negative anomaly. In the second phase both sources changed sign, so they still tend to compensate each other. The models agree that the two sources are out of phase on decadal time scales, and the magnitudes of the two sources are correlated in the models (one term is larger, then the other is also larger).

Note that splitting the sea ice volume sources as done above does not reveal separate roles of thermal forcing and wind forcing. Wind can affect both thermodynamic growth by opening and closing areas of open water, and sea ice export by changing sea ice drift, while air temperature can affect thermodynamic growth directly and ice export by changing sea ice thickness. Using sensitivity experiments Köberle and Gerdes (2003) showed that sea ice export is more closely linked to wind forcing and thermodynamic growth is somewhat more related to thermal forcing on the interannual time scale, but both forcing terms are important on long time scales. Good agreement on the simulated 

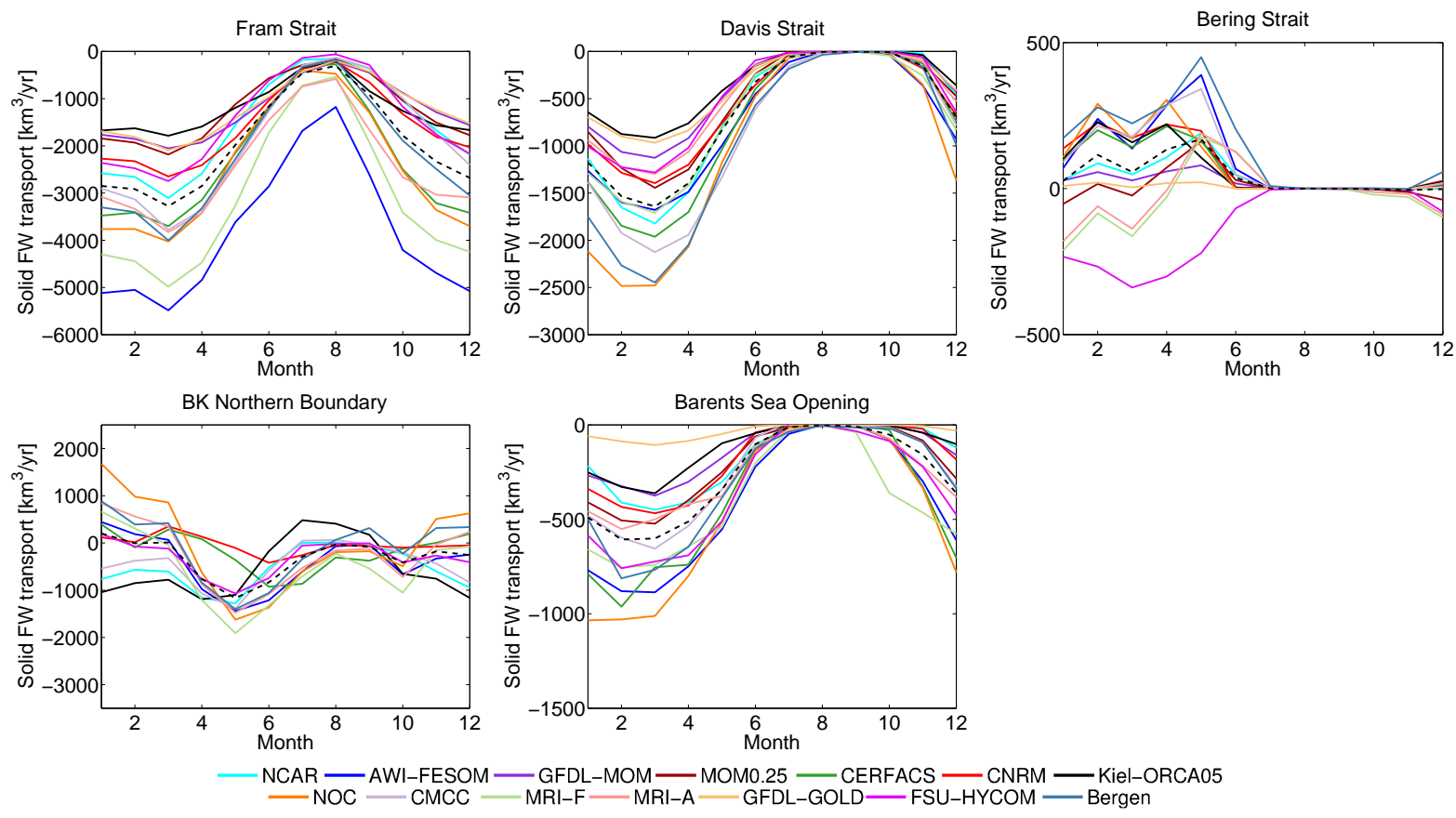

Figure 16: Mean seasonal cycle of solid freshwater transport through the Arctic gateways averaged over the last 30 years $(1978-2007)$. The dashed lines show model ensemble means. Positive transport means source for the Arctic Ocean.

sea ice volume variability indicates that the models can relatively well represent the effect of different atmospheric forcing components.

\subsection{Seasonal variability}

In this section we assess the seasonality of the Arctic solid FW budget. Solid FW export occurs predominantly in wintertime at the Fram Strait, Davis Strait, BSO and BKN (Figure 16). Vanishing transports in summertime are associated with nearly ice-free conditions at Davis Strait, Bering Strait and the BSO. Four models (FSU-HYCOM, MRIF, MRI-A and MOM0.25) simulate export transport in winter at Bering Strait, which is different from other models and observations (Woodgate and Aagaard, 2005). No linkage between model resolution and the magnitude and variability of solid FW transport at Bering Strait is found.

At the BKN, the models have low transport values in the summertime because the transect is close to the summer ice edge. Eight models agree on positive (towards the Arctic Ocean) transports in January. These models are those that produced correct ice flow direction in $1999 / 2000$ (see Section 3.2.1). The seasonality is not found to be 
correlated with sea ice thickness, so the sea ice drift velocity mainly determines the seasonal changes in solid FW transport at the BKN section.

Fram Strait has the largest seasonal variation in solid FW transports among the five gateways. The models agree that the Fram Strait export is the weakest in August. The comparison to observations indicates that all models capture the seasonal changes, but tend to underestimate the export flux in summer and overestimate it in winter (Figure 10). The solid FW export in November is lower than in October in observations and most models in the 1990s (the period of available observations), but this is not seen in the mean seasonal cycle averaged over the last 30 years (compare Figures 10 and 16). This indicates that the details of the seasonal cycle vary on decadal time scales. The spread in winter transports is large among the models (ranging from about 2000 to $5000 \mathrm{~km}^{3} /$ year). Note that the uncertainty in observational estimates used in Figure 10 is also large. Although

the same observed ice thickness profiles are used by Vinje et al. (1998) and Kwok and Rothrock (1999), they obtained ice flux estimates with differences of up to $30 \%$ because they used different ice drift estimates.

The seasonal variation of Arctic sea ice volume is mainly caused by the strong seasonal cycle of sea ice freezing and melting, not the lateral transport (not shown). The models agree on the seasonality of sea ice volume, with maximum in April and minimum in September, although the August (or October) sea ice volume is similar to their September values in a few models (Figure 5). The magnitude of seasonal variation (maximum minus minimum) is the smallest in MRI-A and largest in FSU-HYCOM, and the latter is about $70 \%$ higher than the former. No connection between the magnitude of seasonal variation and the mean sea ice volume is found.

\subsection{Summary on the model ensemble mean of solid freshwater}

In this section we summarize the simulated solid FW budget based on the model ensemble mean. Other general remarks are given in the concluding section (Section 4).

1. Solid FW mean state

- The model ensemble mean represents the canonical scenario of the Arctic solid FW budget: The Arctic Ocean feeds solid FW to the subpolar North Atlantic mainly through Fram Strait, and receives a very small amount of sea 


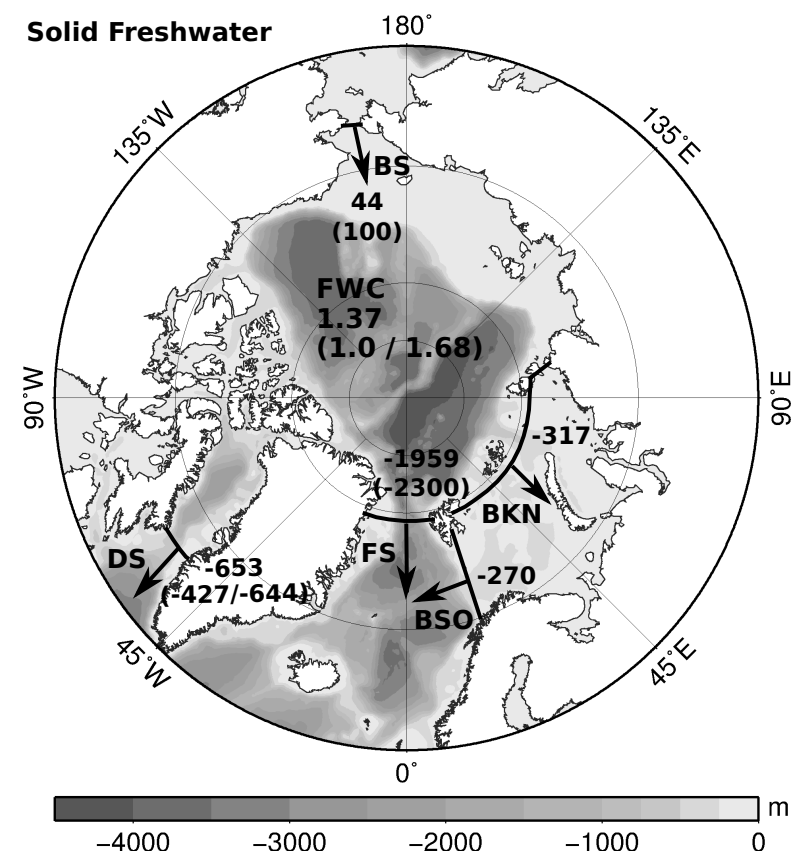

Figure 17: Model ensemble mean of solid freshwater budget of the Arctic Ocean. FW fluxes through the Arctic gateways are shown in $\mathrm{km}^{3} /$ year, and the FWC is in $10^{4} \mathrm{~km}^{3}$. The synthesized climatological values are shown in brackets; see Table 4 for their reference. The five main gateways are shown: Fram Strait (FS), Davis Strait (DS), Bering Strait (BS), Barents/Kara Seas northern boundary (BKN), and southern Barents Sea Opening (BSO). The last 30 model years (1978 - 2007) are used in the calculation.
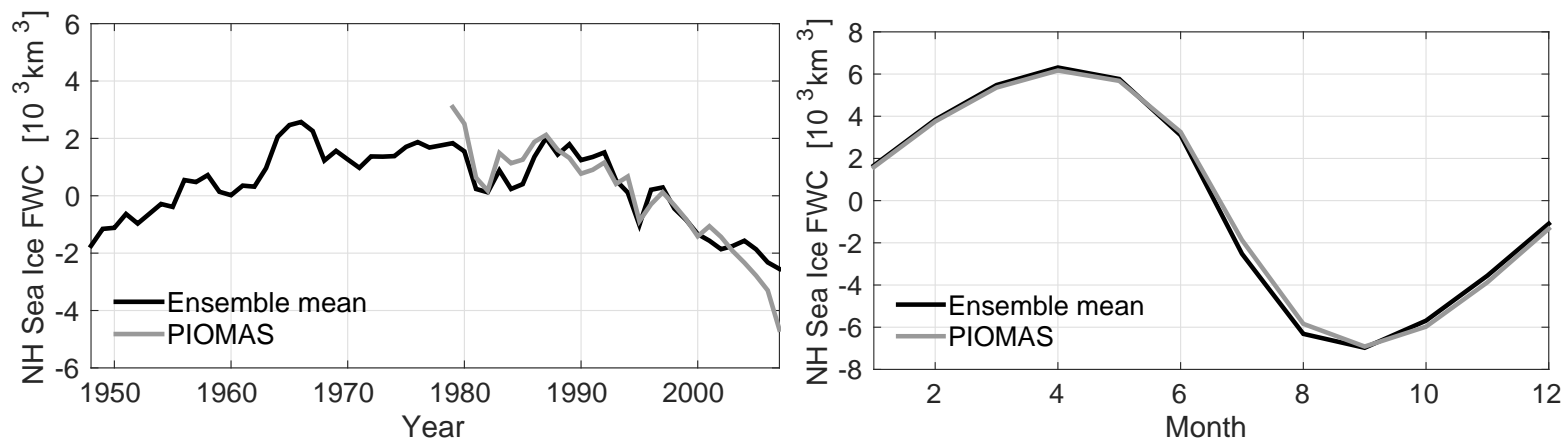

Figure 18: Anomaly of model ensemble mean of solid freshwater content (FWC) in the Arctic Ocean: (left) the annual mean time series and (right) the seasonal cycle. Sea ice FWC derived from PIOMAS Arctic sea ice volume reanalysis (Schweiger et al. 2011) is shown with gray curves; Sea ice density of $910 \mathrm{~kg} / \mathrm{m}^{3}$ and salinity of $4 \mathrm{ppt}$ are assumed. 
ice through Bering Strait (Table 4, Figure 17). On average the models show small export fluxes at Davis Strait and the BKN.

- The simulated mean solid FW export through Fram Strait is $-1959 \mathrm{~km}^{3} /$ year, at the lower bound of the synthesized value $\left(-2300 \pm 340 \mathrm{~km}^{3} /\right.$ year, Serreze et al., 2006; Vinje et al., 1998). The mean solid FW export through Davis Strait is $-653 \mathrm{~km}^{3} /$ year, comparable to the values suggested by observations $\left(-427\right.$ to $-644 \mathrm{~km}^{3} /$ year, Kwok, 2007).

- The synthesized value of FW stored in sea ice has large uncertainty because of lacking continuous observations of ice thickness. It is estimated to be $10^{4} \mathrm{~km}^{3}$ using $2 \mathrm{~m}$ ice thickness by Serreze et al. (2006). The FW stored in sea ice based on the PIOMAS sea ice volume reanalysis (Schweiger et al., 2011) is about $1.68 \times 10^{4} \mathrm{~km}^{3}$ averaged from 1979 to 2007 (assuming sea ice density of $910 \mathrm{~kg} / \mathrm{m}^{3}$ and salinity of $4 \mathrm{ppt}$ ). The model ensemble mean is $1.37 \times 10^{4} \mathrm{~km}^{3}$, within the range of these estimations.

2. Solid FW variability and trend

- The models can reproduce the observed interannual and seasonal variability of sea ice transport at Fram Strait. They simulated the large sea ice export events in the 1960s, 1980s and 1990s which caused the GSAs reported by (Dickson et al., 1988; Hakkinen, 2002) (Figure 11). They also well represented the observed variability of sea ice export described by Vinje et al. (1998); Kwok and Rothrock (1999); Kwok et al. (2004) (Figure 10). By referring to the observation reported by Spreen et al. (2009), Haine et al. (2015) suggest that the solid FW export at Fram Strait has declined by $400 \mathrm{~km}^{3} /$ year in the period 2000 - 2010 (compared to the climatological value of $2300 \pm 340 \mathrm{~km}^{3} /$ year), a reduction at the level of interannual variability. The simulated decline of Fram Strait solid FW flux after 2000 in the model ensemble mean is similar to this synthesized value.

- The model ensemble means captured the observed upward changes of sea ice export at Davis Strait from 2005 to 2007 (Curry et al. 2014) and at the BKN from 1999/2000 to 2002/2003 (Kwok et al., 2005) (Figure 11). 
- Due to lacking continuous sea ice thickness observations, there are no time

\section{Conclusion}

In this work we assessed the Arctic Ocean in 14 models participating in the Coordinated Ocean-ice Reference Experiments, phase II (CORE-II) intercomparison project. All the models are global and the ocean-sea ice components of respective climate models series of solid FW storage that can be directly used to assess model results. Assimilation of sea ice concentration is used by PIOMAS to improve sea ice thickness simulations (Zhang and Rothrock, 2003). The time series of NH sea ice FWC based on the PIOMAS sea ice volume reanalysis (Schweiger et al., 2011) is shown in Figure 18, Both the interannual and seasonal variations are very consistent between the CORE-II model ensemble mean and the PIOMAS result. However, PIOMAS shows a steeper decline in the last few years than the model ensemble mean. The CORE-II models did not adequately reproduce the observed acceleration in the thinning trend after 2003 (Figure 13), which can explain their lower descending trend in sea ice volume compared to the PIOMAS result.

(Danabasoglu et al., 2014). They used the same atmospheric forcing data sets and bulk formula following the CORE-II protocol (Griffies et al., 2012). The atmospheric forcing covers 60 years from 1948 to 2007 (Large and Yeager, 2009), and the models are run for 300 years corresponding to 5 consecutive loops of the 60 -year forcing period. Model configurations including resolution, parameterization, parameters are decided by the model developing groups. In this paper we focus on the Arctic sea ice extent and the sources and storage of Arctic solid freshwater (FW).

The states of the model ensemble means are summarized at the end of each section. Other key points are itemized below.

1. Sea ice extent and concentration

- Although there is a large spread in the Northern Hemisphere mean sea ice extent in the models, its interannual and seasonal variability is largely consistent with the observation (Figures 2 and 5). 
- On average the descending trends in sea ice extent in the period of satellite observation is better simulated for September than for March. Except for four models that have too low sea ice extent, the September descending trend tends to be weaker in models with higher sea ice extent and thickness.

- The models consistently show good correlation between the sea ice extent in Barents Sea and the heat transport through the Barents Sea Opening (BSO) at 0 - 1 year lag (heat transport lead, Figure 6), as suggested in previous studies (Arthun et al. 2012).

\section{Solid FW budget}

- There is large spread in mean sea ice thickness and volume in the models. In both March and September, models with thicker sea ice tend to have larger sea ice volume, except for the four models which have too thin sea ice (Figure 9). The model spread in sea ice volume can largely be explained by the spread in sea ice thickness.

- The models obtained descending trend in sea ice volume over the last 30 years, but there is a spread in the descending rate. The rate is mainly determined by the strength of the descending trend in sea ice thickness (Figure 12). The interannual variability of sea ice volume can be explained by that of sea ice thickness more than sea ice extent. The semi-closed Arctic geometry naturally reduces the sea ice volume sensitivity to sea ice extent.

- Sea ice export through the gateways and the thermodynamic sea ice production tend to compensate each other on decadal time scales (Figure 15). The decreasing sea ice thermodynamic growth rate in the recent decades is accompanied by a reduction in the sea ice export.

- The models tend to underestimate the observed sea ice thinning trend, most significantly after 2003 (Figure 13). It remains to see whether this common issue is related to the atmospheric forcing used in the simulations or due to some general model features.

Overall, the CORE-II models, driven by the same interannually varying atmospheric state, did not demonstrate qualitatively similar mean state in the Arctic Ocean, as also 
found for the North Atlantic (Danabasoglu et al. 2014). The variability of most of the characteristics we explored, is modelled more consistently than the mean state, which is also a conclusion of the CORE-II North Atlantic study (Danabasoglu et al., 2015). It is noticed that the model spread in the mean state is larger than the interannual variability magnitude for many of the diagnostics. When we evaluate the model ensemble means, it is found that both the variability and mean state are reasonably reproduced. These conclusions apply to both the solid FW shown in this paper and the liquid FW state presented in Wang et al. (2015). It is shown that the CORE-II models tend to underestimate the descending trends in sea ice thickness and March sea ice extent. It is necessary for the model development groups to work on the common issues for the important roles played by sea ice in the climate system.

It is worth pointing out that not all the conclusions based on the CORE-II models can be directly transferred to their respective coupled climate models. For example, the NCAR model is one of the models with very low sea ice thickness (Figure 8), but it has much thicker sea ice in the coupled climate model (CCSM4) simulation for the late 20th century, using the same model resolution and parameters (Jahn et al., 2012b $)^{8}$. Therefore the results presented in this work should be interpreted with caution when the context is extended to coupled models.

In this work we focused on the discussion of the difference and similarity between the results of CORE-II simulations and observations, and tried to provide information on common issues and possible linkages between different key diagnostics used in the discussion. Such information can be helpful for further improving models, but dedicated studies of model sensitivity to physical and numerical parameters are necessary in order to reduce model uncertainties identified through model intercomparisons.

\footnotetext{
${ }^{8}$ Simulated sea ice thickness can be significantly influenced by the choice of albedos. At NCAR, the same albedos were used for both the fully-coupled model simulations and the CORE-II experiments. The albedos were partly adjusted to help tune the top-of-the-atmosphere heat flux in the coupled preindustrial control simulation. With the chosen albedos, the simulated sea ice thickness in the coupled simulation is very reasonable, while it is underestimated in the CORE-II simulation.
} 


\section{Acknowledgements}

The WCRP/CLIVAR Ocean Model Development Panel (OMDP) is responsible for organising the Coordinated Ocean-sea ice Reference Experiments, with support from the international CLIVAR and U.S. CLIVAR project offices. We are grateful for the efforts of modellers who have contributed to the simulation and processing of the CORE-II experiments. We thank Randi Ingvaldsen for providing us with the ocean transport data at the Barents Sea Opening. Comments by two reviewers and Claudia Wekerle, Richard Greatbatch and Tor Eldevik helped to improve the manuscript. AWI is a member of the Helmholtz Association of German Research Centers. Q. Wang is funded by the Helmholtz Climate Initiative REKLIM (Regional Climate Change) project. C. Roth was supported by the Co-Operative Project RACE-Regional Atlantic Circulation and Global Change funded by the German Federal Ministry for Education and Research (BMBF), grant no. 03F0651B. The BERGEN contribution is supported by the Research Council of Norway through the EarthClim (207711/E10) and NOTUR/NorStore projects, as well as the Centre for Climate Dynamics at the Bjerknes Centre for Climate Research. The CMCC contribution received funding from the Italian Ministry of Education, University, and Research and the Italian Ministry of Environment, Land, and Sea under the GEMINA project. NCAR is sponsored by the U. S.National Science Foundation (NSF). S.G. Yeager was supported by the NOAA Climate Program Office under Climate Variability and Predictability Program Grant NA09OAR4310163 and NA13OAR4310138 and by the NSF Collaborative Research EaSM2 grant OCE-1243015 to NCAR. The AWI-FESOM and Kiel-ORCA05 experiments were performed at the North-German Supercomputing Alliance (HLRN).

\section{Appendix A. Sea ice models used in the CORE-II simulations} CICE v.4

The Los Alamos National Laboratory sea ice model version 4 (CICE 4, Hunke and Lipscomb 2008) includes the energy-conserving thermodynamics by Bitz and Lipscomb (1999), the elastic-viscous-plastic dynamics by Hunke and Dukowicz (2002), and a subgridscale representation of ice thickness distribution (ITD) following Thorndike et al. (1975). 
The ITD uses five categories within each grid cell, which have different thickness, surface properties, and melt and growth rates as computed by the thermodynamics. It has four ice layers and one snow layer in each of the five thickness categories. The model includes a radiative transfer scheme (Briegleb and Light, 2007) and associated capabilities to sim-

ulate explicitly melt pond evolution, and the deposition, cycling, and radiative impacts of aerosols (dust and black carbon) on sea ice. This scheme calculates multiple scattering of solar radiation in sea ice using a delta-Eddington approximation with inherent optical properties to compute apparent optical properties (including albedo). The mechanical deformation takes into account ridging and rafting processes (Rothrock, 1975), and uses a modified expression for the participation function (Lipscomb et al., 2007). The advection scheme uses a two-dimensional, linear incremental remapping method (Lipscomb and Hunke, 2004). A similar, one-dimensional linear remapping scheme (Lipscomb, 2001) transfers ice among ITD categories upon changes in thermodynamic, ridging, and advective ice thickness. CICE v.4 is used in three CORE-II models (Bergen, CMCC and NCAR).

\section{CSIM v. 5}

The community Sea Ice Model (CSIM) is a dynamic-thermodynamic model that is closely related to CICE version 3.1. It includes a subgrid-scale ice thickness distribution and uses the energy conserving thermodynamics of Bitz and Lipscomb (1999), with four ice layers and one snow layer in each of the five thickness categories. The ice dynamics is based on the elastic-viscous-plastic rheology of Hunke and Dukowicz (1997) and the subgrid-scale ridging and rafting is parameterized according to Rothrock (1975) and Thorndike et al. (1975). The horizontal advection is calculated via the incremental remapping scheme of Lipscomb and Hunke (2004). The shortwave albedo depends on the ice and snow thickness as well as the temperature and is calculated with the visible and near infrared radiative bands. CSIM v.5 is used in FSU.

FESIM v.2

Finite Element Sea Ice Model version 2 (FESOM v.2, Danilov et al., 2015) is a dynamic-thermodynamic sea ice model on unstructured meshes. It uses the same triangular meshes as its counterpart ocean model (FESOM, Wang et al., 2014). The model 
employs the Parkinson and Washington (1979) thermodynamics. It includes a prognostic snow layer (Owens and Lemke, 1990) with the effect of snow-ice conversion due to flooding accounted. Heat storage in ice and snow is neglected, so that linear temperature profiles in both layers are assumed (so-called zero-layer approach of Semtner, 1976). For the computation of ice (and snow) drift, the model provides options of the viscous-plastic (VP, Hibler, 1979), the elastic- viscous-plastic (EVP, Hunke and Dukowicz, 1997; Hunke, 2001) and the modified EVP (mEVP, Bouillon et al., 2013) rheologies. In the AWIFESOM CORE-II simulation the EVP rheology was used. The dry and wet ice albedos are set to 0.7 and 0.68 , respectively; and the dry and wet snow albedos are set to 0.81 and 0.77 , respectively.

\section{Gelato v.5}

Gelato is a multi-category, enthalpy model with prognostic sea ice salinity. In the present study, 4 ice thickness categories are considered: $0-0.3 \mathrm{~m}, 0.3-0.8 \mathrm{~m}, 0.8-3 \mathrm{~m}$ and over $3 \mathrm{~m}$. Transitions or mergers between these categories may occur as ice thickness varies thermodynamically or due to sea ice transport and redistribution through rafting and ridging. Every ice category has 9 vertical layers in the ice part of the slab, and can be covered with one layer of snow, for which snow ageing and snow-ice formation processes are considered (Salas Mélia, 2002). The albedo of bare, dry ice albedo is a function of thickness (Flato and Brown, 1996). However, this albedo is modulated by the age of sea ice: if an ice slab is older than 6 months its albedo is relaxed to the albedo of thick, dry ice. The albedo of melting bare ice is a model parameter (equal to 0.56 in the simulation), since this albedo implicitly includes the contribution of surface melt ponds, ${ }$ which are not modeled by GELATO. The albedo of snow is as specified by Flato and Brown (1996). The salinity of sea ice is a prognostic variable, following Vancoppenolle et al. (2009). Ice velocity is computed following Hunke and Dukowicz (1997), and sea ice transport is represented by an incremental remapping scheme (Lipscomb, 2001). Gelato v.5 is used in CNRM.

LIM v.2

The Louvain-la-Neuve sea ice model version 2 (LIM v.2, Fichefet and Maqueda, 1997; 855 Bouillon et al., 2009) is a dynamic-thermodynamic sea ice model with three layers (one 
layer for snow and two layers for ice). Vertical and lateral sea ice growth/decay rates are obtained from energy budgets at the upper and lower surfaces of the snowice cover, and at the surface of leads present within the ice pack. It allows seawater to infiltrate the snow-ice interface, when the load of snow is large enough to form a snow ice cap.

The surface albedo depends on the state of the surface, the thickness of the snow and ice covers and sky conditions. The model uses elastic-viscous-plastic (EVP) ice rheology (Hunke and Dukowicz, 2002). LIM v.2 is used in CERFACS, Kiel-ORCA05 and NOC.

\section{$M K 89-C I C E$}

The sea ice model MK89-CICE is based on Mellor and Kantha (1989), but the treatment of thickness categorization, ridging, rheology, and albedo follows the Los Alamos sea ice model (CICE, Hunke and Lipscomb, 2010). There is one-layer sea ice with heat content overlain by one-layer snow without heat content. Sea ice in a grid cell is divided into five thickness categories. Fractional area, snow volume, ice volume, ice energy, and ice surface temperature of each thickness category are transported using multidimensional positive definite advection transport algorism (MPDATA, Smolarkiewicz, 1984). Formulation of sea ice albedo is based on the default (CCSM3) method in the Los Alamos sea ice model with some modifications of parameters. Downward shortwave radiation is partitioned with a fixed ratio: 0.575 for visible and 0.425 for near infrared. The bare ice albedo is raised from the default value: 0.8 for visible wave lengths and 0.58 for near infrared wave lengths. Other parameters are the same as listed in the CICE manual. In MRI models the bulk transfer coefficient over sea ice is $3.0 \times 10^{-3}$ for momentum and $1.5 \times 10^{-3}$ for specific heat and sublimation as used by Mellor and Kantha (1989). MK89-CICE is used in MRI-F and MRI-A.

\section{SIS v.1}

Sea Ice Simulator (SIS v.1) is a dynamical-thermodynamical sea-ice model where the elastic-viscous-plastic rheology (Hunke and Dukowicz, 1997) is used to calculate ice internal stresses and the thermodynamics is represented by a modified Semtner scheme from Winton (2000). SIS has three vertical layers, including one layer of snow cover and two layers of equally sized sea ice. In each model grid, five categories of sea ice are considered, according to the thickness of sea ice. A simple scheme moves ice between 
categories when category thickness bounds are transgressed due to thermodynamic or dynamic changes. It has no ridging parameterization. The albedo parameterization is anchored to fixed snow and ice albedos (Briegleb et al. 2002$)$. Broadband dry albedos for snow and ice are 0.85 and 0.65, respectively. SIS v.1 is used in GFDL-MOM, MOM0.25 and GFDL-GOLD.

\section{Appendix B. Definition of freshwater content and transport}

The Arctic sea ice freshwater content (FWC) is defined as

$$
\iint_{\mathrm{A}} \frac{S_{r e f}-S_{i}}{S_{r e f}} \frac{\rho_{i}}{\rho_{o}} h_{i} d s
$$

where the integration is taken over the Arctic surface area $\mathrm{A}, h_{i}$ is the effective sea ice thickness (mean thickness in a grid cell), $\rho_{o}$ is the reference ocean density (in the model it is used for the volume conversion between water and sea ice), $\rho_{i}$ is the sea ice density.

The Arctic sea ice freshwater transport through a transect is defined as

$$
\iint_{L} \frac{S_{r e f}-S_{i}}{S_{r e f}} \frac{\rho_{i}}{\rho_{o}} h_{i} v_{i} d l
$$

where the integration is taken over the section line $L, v_{i}$ is the ice drift velocity normal to the transect. Snow freshwater content and transport are defined similarly by using snow effective thickness, salinity and density. Total solid freshwater transport is the sum of sea ice and snow freshwater transports.

\section{References}

\section{References}

Aagaard, K., Carmack, E.C., 1989. The role of sea ice and other fresh-water in the Arctic circulation. J. Geophys. Res. 94, 14485-14498.

Aagaard, K., Swift, J.H., Carmack, E., 1985. Thermohaline circulation in the Arctic mediterranean seas. Journal of Geophysical Research-oceans 90, 4833-4846.

Arthun, M., Eldevik, T., Smedsrud, L.H., Skagseth, O., Ingvaldsen, R.B., 2012. Quantifying the Influence of Atlantic Heat on Barents Sea Ice Variability and Retreat. Journal of Climate 25, 4736-4743. 
Bacon, S., Aksenov, Y., Fawcett, S., Madec, G., 2015. Arctic mass, freshwater and heat fluxes: methods and modelled seasonal variability. Phil. Trans. R. Soc. A 373, 20140169.

Bhatt, U.S., Walker, D.A., Walsh, J.E., Carmack, E.C., Frey, K.E., Meier, W.N., Moore, S.E., Parmentier, F.J.W., Post, E., Romanovsky, V.E., Simpson, W.R., 2014. Implications of Arctic sea ice decline for the Earth System. Annual Review of Environment and Resources 39, 57-89.

Bitz, C.M., Lipscomb, W.H., 1999. An energy-conserving thermodynamic model of sea ice. J. Geophys. Res.-oceans 104, 15669-15677.

Bouillon, S., Fichefet, T., Legat, V., Madec, G., 2013. The elastic-viscous-plastic method revisited. Ocean Modelling 71, 2-12.

Bouillon, S., Maqueda, M., Legat, V., Fichefet, T., 2009. An elastic-viscous-plastic sea ice model formulated on Arakawa B and C grids. Ocean Modell. 27, 174-184.

Briegleb, B.P., Bitz, C., Hunke, E., Lipscomb, W., J.L., S., 2002. Description of the Community Climate System Model Version 2: Sea Ice Model. Technical Report pp62. National Center for Atmospheric Research.

Briegleb, B.P., Light, B., 2007. A delta-Eddington multiple scattering parameterization for solar radiation in the sea ice component of the Community Climate System Model. Technical Report TN-472+STR, 100 pp.. NCAR.

Carmack, E., Yamamoto-Kawai, M., Haine, T., Bacon, S., Bluhm, B., Lique, C., Melling, H., Polyakov, I., Straneo, F., Timmermans, M..L., Williams, W., 2015. Fresh water and its role in the Arctic Marine System: sources, disposition, storage, export, and physical and biogeochemical consequences in the Arctic and global oceans. J. Geophys. Res. Biogeosciences doi:10.1002/2015JG003140.

Cavalieri, D.J., Parkinson, C.L., 2012. Arctic sea ice variability and trends, 1979-2010. Cryosphere 6, 881-889. 
Comiso, J.C., 2012. Large decadal decline in the Arctic multiyear ice cover. J. Clim. 25, $1176-1193$.

Comiso, J.C., Nishio, F., 2008. Trends in the sea ice cover using enhanced and compatible AMSR-E, SSM/I, and SMMR data. J. Geophys. Res.- Oceans 113, C02S07.

Comiso, J.C., Parkinson, C.L., Gersten, R., Stock, L., 2008. Accelerated decline in the Arctic sea ice cover. Geophys. Res. Lett. 35, L01703.

Curry, B., Lee, C.M., Petrie, B., Moritz, R.E., Kwok, R., 2014. Multiyear volume, liquid freshwater, and sea ice transports through Davis Strait, 2004-2010. Journal of Physical Oceanography 44, 1244-1266.

Danabasoglu, G., Yeager, S.G., Bailey, D., Behrens, E., Bentsen, M., Bi, D., Biastoch, A., Böning, C., Bozec, A., Canuto, V.M., Cassou, C., Chassignet, E., Coward, A.C., Danilov, S., Diansky, N., Drange, H., Farneti, R., Fernandez, E., Fogli, P.G., Forget, G., Fujii, Y., Griffies, S.M., Gusev, A., Heimbach, P., Howard, A., Jung, T., Kelley, M., Large, W.G., Leboissetier, A., Lu, J., Madec, G., Marsland, S.J., Masina, S., Navarra, A., Nurser, A.G., Pirani, A., y Melia, D.S., Samuels, B.L., Scheinert, M., Sidorenko, D., Treguier, A.M., Tsujino, H., Uotila, P., Valcke, S., Voldoire, A., Wang, Q., 2014. North Atlantic simulations in Coordinated Ocean-ice Reference Experiments phase $\{$ II $\}$ (CORE-II). part i: Mean states. Ocean Modelling 73, 76 - 107.

Danabasoglu, G., Yeager, S.G., Bailey, D., Behrens, E., Bentsen, M., Bi, D., Biastoch, A., Böning, C., Bozec, A., Canuto, V.M., Cassou, C., Chassignet, E., Coward, A.C., Danilov, S., Diansky, N., Drange, H., Farneti, R., Fernandez, E., Fogli, P.G., Forget, G., Fujii, Y., Griffies, S.M., Gusev, A., Heimbach, P., Howard, A., Jung, T., Kelley, M., Large, W.G., Leboissetier, A., Lu, J., Madec, G., Marsland, S.J., Masina, S., Navarra, A., Nurser, A.G., Pirani, A., y Melia, D.S., Samuels, B.L., Scheinert, M., Sidorenko, D., Treguier, A.M., Tsujino, H., Uotila, P., Valcke, S., Voldoire, A., Wang, Q., 2015. North Atlantic simulations in Coordinated Ocean-ice Reference Experiments phase $\{$ II $\}$ (CORE-II). part ii: Inter-annual to decadal variability. Ocean Modelling, submitted. 
Danilov, S., Wang, Q., Timmermann, R., Iakovlev, N., Sidorenko, D., Kimmritz, M., Jung, T., Schroeter, J., 2015. Finite-Element Sea Ice Model (FESIM), version 2. Geoscientific Model Development 8, 1747-1761.

Dickson, R., Meincke, J., Malmberg, S., Lee, A.J., 1988. The Great Salinity Anomaly In the Northern North-atlantic 1968-1982. Progress In Oceanography 20, 103-151.

Dickson, R., Rudels, B., Dye, S., Karcher, M., Meincke, J., Yashayaev, I., 2007. Current estimates of freshwater flux through Arctic and subarctic seas. Prog. Oceanogr. 73, $210-230$.

Dickson, R.R., Osborn, T.J., Hurrell, J.W., Meincke, J., Blindheim, J., Adlandsvik, B., Vinje, T., Alekseev, G., Maslowski, W., 2000. The Arctic Ocean Response to the North Atlantic Oscillation. J. Climate 13, 2671 - 2696.

Fetterer, F., Knowles, K., Meier, W., M., S., 2002. Sea Ice Index. Boulder, Colorado USA: National Snow and Ice Data Center. Digital media, updated daily.

Fichefet, T., Maqueda, M.A.M., 1997. Sensitivity of a global sea ice model to the treatment of ice thermodynamics and dynamics. J. Geophys. Res.-oceans 102, 12609-12646.

Flato, G.M., Brown, R.D., 1996. Variability and climate sensitivity of landfast Arctic sea ice. J. Geophys. Res.-oceans 101, 25767-25777.

Goosse, H., Fichefet, T., Campin, J.M., 1997. The effects of the water flow through the Canadian Archipelago in a global ice-ocean model. Geophysical Research Letters 24, $1507-1510$.

Griffies, S., Winton, M., Samuels, B., Danabasoglu, G., Yeager, S., Marlsand, S., Drange, H., Bentsen, M., 2012. Datasets and protocol for the CLIVAR WGOMD Coordinated Ocean-sea ice Reference Experiments (COREs). Technical Report 21. WCRP Report. of great salinity anomalies. Geophysical Research Letters 30, 1473. 
Haine, T., Curry, B., Gerdes, R., Hansen, E., Karcher, M., Lee, C., Rudels, B., Spreen, G., de Steur, L., Stewart, K., Woodgate, R., 2015. Arctic freshwater export: Status, mechanisms, and prospects. Global and Planetary Change 125, 13 - 35.

Hakkinen, S., 1999. A simulation of thermohaline effects of a great salinity anomaly. Journal of Climate 12, 1781-1795.

Hakkinen, S., 2002. Freshening of the Labrador Sea surface waters in the 1990s: Another great salinity anomaly? Geophysical Research Letters 29, 2232.

Hibler, W., 1979. A dynamic thermodynamic sea ice model. J. Phys. Oceanogr. 9, $815-846$.

Holland, M.M., Finnis, J., Barrett, A.P., Serreze, M.C., 2007. Projected changes in Arctic Ocean freshwater budgets. Journal of Geophysical Research-biogeosciences 112, G04S55.

Holloway, G., Dupont, F., Golubeva, E., Haekkinen, S., Hunke, E., Jin, M., Karcher, M., Kauker, F., Maltrud, M., Maqueda, M.A.M., Maslowski, W., Platov, G., Stark, D., Steele, M., Suzuki, T., Wang, J., Zhang, J., 2007. Water properties and circulation in Arctic Ocean models. Journal of Geophysical Research-oceans 112, C04S03.

Hunke, E., Dukowicz, J., 1997. An elastic-viscous-plastic model for sea ice dynamics. J. Phys. Oceanogr. 27, 1849-1867.

Hunke, E.C., 2001. Viscous-plastic sea ice dynamics with the EVP model: Linearization issues. J. Comp. Phys 170, 18-38.

Hunke, E.C., Dukowicz, J.K., 2002. The elastic-viscous-plastic sea ice dynamics model in general orthogonal curvilinear coordinates on a sphere-incorporation of metric terms. Mon. Wea. Rev. 130, 1848-1865.

Hunke, E.C., Lipscomb, W.H., 2010. CICE: the Los Alamos Sea Ice Model Documentation and Software User's Manual, version 4.1. Technical Report LA-CC-06-012, 76pp. Los Alamos National Laboratory. 
Ilicak, M., Drange, H., Wang, Q., Gerdes, R., et al., 2015. An assessment of the Arctic Ocean in a suite of interannual CORE-II simulations. Part III: Hydrohraphy and fluxes. Ocean Modell. , under revision.

Jahn, A., Aksenov, Y., de Cuevas, B.A., de Steur, L., Hakkinen, S., Hansen, E., Herbaut, C., Houssais, M..N., Karcher, M., Kauker, F., Lique, C., Nguyen, A., Pemberton, P., Worthen, D., Zhang, J., 2012a. Arctic Ocean freshwater: How robust are model simulations? J. Geophys. Res. - Oceans 117, C00D16.

Jahn, A., Sterling, K., Holland, M.M., Kay, J.E., Maslanik, J.A., Bitz, C.M., Bailey, D.A., Stroeve, J., Hunke, E.C., Lipscomb, W.H., Pollak, D.A., 2012b. Late-TwentiethCentury Simulation of Arctic Sea Ice and Ocean Properties in the CCSM4. Journal of Climate 25, 1431-1452.

Johnson, M., Gaffigan, S., Hunke, E., Gerdes, R., 2007. A comparison of Arctic Ocean sea ice concentration among the coordinated AOMIP model experiments. Journal of Geophysical Research-Oceans 112, C04S11.

Johnson, M., Proshutinsky, A., Aksenov, Y., Nguyen, A.T., Lindsay, R., Haas, C., Zhang, J., Diansky, N., Kwok, R., Maslowski, W., Haekkinen, S., Ashik, I., de Cuevas, B., 2012. Evaluation of Arctic sea ice thickness simulated by Arctic Ocean Model Intercomparison Project models. Journal of Geophysical Research-oceans 117, C00D13.

Jungclaus, J.H., Haak, H., Latif, M., Mikolajewicz, U., 2005. Arctic-North Atlantic interactions and multidecadal variability of the meridional overturning circulation. Journal of Climate 18, 4013-4031.

Karcher, M., Beszczynska-Moeller, A., Kauker, F., Gerdes, R., Heyen, S., Rudels, B., Schauer, U., 2011. Arctic Ocean warming and its consequences for the Denmark Strait overflow. Journal of Geophysical Research-oceans 116, C02037.

Karcher, M., Kauker, F., Gerdes, R., Hunke, E., Zhang, J., 2007. On the dynamics of Atlantic Water circulation in the Arctic Ocean. J. Geophys. Res. - Oceans 112, C04S02.

Köberle, C., Gerdes, R., 2003. Mechanisms determining the variability of Arctic sea ice conditions and export. Journal of Climate 16, 2843-2858. 
Koenigk, T., Brodeau, L., Graversen, R., Karlsson, J., Svensson, G., Tjernström, M., Willén, U., Wyser, K., 2013. Arctic climate change in 21st century CMIP5 simulations with EC-Earth. Climate Dynamics 40, 2719-2743.

Koenigk, T., Mikolajewicz, U., Haak, H., Jungclaus, J., 2006. Variability of Fram Strait sea ice export: causes, impacts and feedbacks in a coupled climate model. Climate Dynamics 26, 17-34.

Kwok, R., 2007. Baffin Bay ice drift and export: 2002-2007. Geophysical Research Letters 34, L19501.

Kwok, R., 2009. Outflow of Arctic Ocean Sea Ice into the Greenland and Barents Seas: 1979-2007. Journal of Climate 22, 2438-2457.

Kwok, R., Cunningham, G.F., Pang, S.S., 2004. Fram Strait sea ice outflow. Journal of Geophysical Research-oceans 109, C01009.

Kwok, R., Cunningham, G.F., Wensnahan, M., Rigor, I., Zwally, H.J., Yi, D., 2009. Thinning and volume loss of the Arctic Ocean sea ice cover: 2003-2008. Journal of Geophysical Research-oceans 114, C07005.

Kwok, R., Maslowski, W., Laxon, S.W., 2005. On large outflows of Arctic sea ice into the Barents Sea. Geophysical Research Letters 32, L22503.

Kwok, R., Rothrock, D.A., 1999. Variability of Fram Strait ice flux and North Atlantic Oscillation. Journal of Geophysical Research-oceans 104, 5177-5189.

Kwok, R., Rothrock, D.A., 2009. Decline in arctic sea ice thickness from submarine and icesat records: 1958-2008. Geophysical Research Letters 36, L15501.

Large, W.G., Yeager, S.G., 2009. The global climatology of an interannually varying air-sea flux data set. Climate Dynamics 33, 341-364.

Laxon, S., Peacock, N., Smith, D., 2003. High interannual variability of sea ice thickness in the Arctic region. Nature 425, 947-950. 
Laxon, S.W., Giles, K.A., Ridout, A.L., Wingham, D.J., Willatt, R., Cullen, R., Kwok, R., Schweiger, A., Zhang, J., Haas, C., Hendricks, S., Krishfield, R., Kurtz, N., Farrell, S., Davidson, M., 2013. CryoSat-2 estimates of Arctic sea ice thickness and volume. Geophys. Res. Lett. 40, 732-737.

Lipscomb, W.H., 2001. Remapping the thickness distribution in sea ice models. J. Geophys. Res.-oceans 106, 13989-14000.

Lipscomb, W.H., Hunke, E.C., 2004. Modeling sea ice transport using incremental remapping. Mon. Wea. Rev. 132, 1341-1354.

Lipscomb, W.H., Hunke, E.C., Maslowski, W., Jakacki, J., 2007. Ridging, strength, and stability in high-resolution sea ice models. J. Geophys. Res.-oceans 112, C03S91.

Mellor, L.G., Kantha, L., 1989. An ice-ocean coupled model. J. Geophys. Res. 94, 10937-10954.

Owens, W., Lemke, P., 1990. Sensitivity studies with a sea ice-mixed layer-pycnocline model in the Weddell Sea. J. Geophys. Res. - Oceans 95, 9527-9538.

Parkinson, C., Washington, W., 1979. A large-scale numerical model of sea ice. J. Geophys. Res. - Oceans 84, 311-337.

Parkinson, C.L., Cavalieri, D.J., 2008. Arctic sea ice variability and trends, 1979-2006. Journal of Geophysical Research-oceans 113, C07003.

Parkinson, C.L., Cavalieri, D.J., Gloersen, P., Zwally, H.J., Comiso, J.C., 1999. Arctic sea ice extents, areas, and trends, 1978-1996. Journal of Geophysical Research-oceans 104, 20837-20856.

Proshutinsky, A., Aksenov, Y., Kinney, J.C., Gerdes, R., Golubeva, E., Holland, D., Holloway, G., Jahn, A., Johnson, M., Popova, E., Steele, M., Watanabe, E., 2011. Recent Advances in Arctic Ocean Studies Employing Models from the Arctic Ocean Model Intercomparison Project. Oceanography 24, 102-113. 
Rampal, P., Weiss, J., Dubois, C., Campin, J., 2011. Ipcc climate models do not capture Arctic sea ice drift acceleration: Consequences in terms of projected sea ice thinning and decline. J. Geophys. Res. 116, C00D07.

Rawlins, M.A., Steele, M., Holland, M.M., Adam, J.C., Cherry, J.E., Francis, J.A., Groisman, P.Y., Hinzman, L.D., Huntington, T.G., Kane, D.L., Kimball, J.S., Kwok, R., Lammers, R.B., Lee, C.M., Lettenmaier, D.P., McDonald, K.C., Podest, E., Pundsack, J.W., Rudels, B., Serreze, M.C., Shiklomanov, A., Skagseth, O., Troy, T.J., Voeroesmarty, C.J., Wensnahan, M., Wood, E.F., Woodgate, R., Yang, D., Zhang, K., Zhang, T., 2010. Analysis of the Arctic system for freshwater cycle intensification: Observations and expectations. Journal of Climate 23, 5715-5737.

Rothrock, D., 1975. Energetics of plastic-deformation of pack ice by ridging. J. Geophys. Res.-oceans and Atmospheres 80, 4514-4519.

Rothrock, D.A., Percival, D.B., Wensnahan, M., 2008. The decline in Arctic sea-ice thickness: Separating the spatial, annual, and interannual variability in a quarter century of submarine data. J. Geophys. Res. 113, C05003.

Rothrock, D.A., Yu, Y., Maykut, G.A., 1999. Thinning of the Arctic sea-ice cover. Geophysical Research Letters 26, 3469-3472.

Rudels, B., Friedrich, H., 2000. The transformation of the Atlantic Water in the Arctic Ocean and their significance for the freshwaer budget, in: Lewis, E.L.e.a. (Ed.), The Freshater Budget of the Arctic Ocean. Kluwer, pp. 503-532.

Salas Mélia, D., 2002. A global coupled sea ice-ocean model. Ocean Modell. 4, 137-172.

Schweiger, A., Lindsay, R., Zhang, J., Steele, M., Stern, H., Kwok, R., 2011. Uncertainty in modeled Arctic sea ice volume. Journal of Geophysical Research-oceans 116, C00D06.

Serreze, M.C., Barrett, A.P., Slater, A.G., Woodgate, R.A., Aagaard, K., Lammers, R.B., Steele, M., Moritz, R., Meredith, M., Lee, C.M., 2006. The large-scale freshwater cycle of the Arctic. J. Geophys. Res. - Oceans 111, C11010. 
Serreze, M.C., Barry, R.G., 2011. Processes and impacts of Arctic amplification: A research synthesis. Global and Planetary Change 77, 85-96.

Serreze, M.C., Holland, M.M., Stroeve, J., 2007. Perspectives on the Arctic's shrinking sea-ice cover. Science 315, 1533-1536.

Smedsrud, L.H., Esau, I., Ingvaldsen, R.B., Eldevik, T., Haugan, P.M., Li, C., Lien, V.S., Olsen, A., Omar, A.M., Ottera, O.H., Risebrobakken, B., Sando, A.B., Semenov, V.A., Sorokina, S.A., 2013. The role of the Barents Sea in the Arctic climate system. Reviews of Geophysics 51, 415-449.

Smolarkiewicz, P.K., 1984. A fully multidimensional positive definite advection transport algorism with small implicit diffusion. J. Comput. Phys. 54, 325-362.

Spreen, G., Kern, S., Stammer, D., Hansen, E., 2009. Fram Strait sea ice volume export estimated between 2003 and 2008 from satellite data. Geophys. Res. Lett. 36, L19502.

Stroeve, J., Serreze, M., Drobot, S., Gearheard, S., Holland, M., Maslanik, J., Meier, W., Scambos, T., 2008. Arctic sea ice extent plummets in 2007, AGU. pp. 13-14.

Stroeve, J.C., Kattsov, V., Barrett, A., Serreze, M., Pavlova, T., Holland, M., Meier, W.N., 2012a. Trends in Arctic sea ice extent from CMIP5, CMIP3 and observations. Geophysical Research Letters 39, L16502.

Stroeve, J.C., Serreze, M.C., Holland, M.M., Kay, J.E., Malanik, J., Barrett, A.P., 2012b. The arctic's rapidly shrinking sea ice cover: a research synthesis. Climatic Change 110, $1005-1027$.

Thorndike, A., Rothrock, D., Maykut, G., Colony, R., 1975. The thickness distribution of sea ice. J. Geophys. Res. 80, 4501-4513.

Vancoppenolle, M., Fichefet, T., Goosse, H., Bouillon, S., Madec, G., Maqueda, M.A.M., 2009. Simulating the mass balance and salinity of Arctic and Antarctic sea ice. 1. model description and validation. Ocean Modelling 27, 33-53.

Vinje, T., 2001. Fram strait ice fluxes and atmospheric circulation: 1950-2000. Journal of Climate 14, 3508-3517. 
Vinje, T., Nordlund, N., Kvambekk, A., 1998. Monitoring ice thickness in Fram Strait. Journal of Geophysical Research-oceans 103, 10437-10449.

Wadley, M.R., Bigg, G.R., 2002. Impact of flow through the Canadian Archipelago and Bering Strait on the north Atlantic and Arctic circulation: An ocean modelling study. Quarterly Journal of the Royal Meteorological Society 128, 2187-2203.

Wang, Q., Danilov, S., Sidorenko, D., Timmermann, R., Wekerle, C., Wang, X., Jung, T., Schröter, J., 2014. The Finite Element Sea Ice-Ocean Model (FESOM) v.1.4: formulation of an ocean general circulation model. Geosci. Model Dev. 7, 663-693.

Wang, Q., Ilicak, M., Gerdes, R., Drange, H., Aksenov, Y., Bailey, D., Bentsen, M., Biastoch, A., Bozec, A., Böning, C., Cassou, C., Chassignet, E., Coward, A., Curry, B., Danabasoglu, G., Danilov, S., Fernandez, E., Fogli, P., Fujii, Y., Griffies, S., Iovino, D., Jahn, A., Jung, T., Large, W., Lee, C., Lique, C., Lu, J., Masina, S., Nurser, A., Rabe, B., Roth, C., Salas y Mélia, D., Samuels, B., Spence, P., Tsujino, H., Valcke, S., Voldoire, A., Wang, X., Yeager, S., 2015. An assessment of the Arctic Ocean in a suite of interannual CORE-II simulations. Part II: Liquid freshwater. Ocean Modell. , under revision.

Wang, Q., Myers, P., Hu, X., Bush, A., 2012. Flow constraints on pathways through the Canadian Arctic Archipelago. Atmosphere-ocean 50, 373-385.

Winton, M., 2000. A reformulated three-layer sea ice model. J. Atmos. Oceanic Technol. $17,525-531$.

Woodgate, R.A., Aagaard, K., 2005. Revising the Bering Strait freshwater flux into the Arctic Ocean. Geophysical Research Letters 32, L02602.

Zhang, J.L., Rothrock, D.A., 2003. Modeling global sea ice with a thickness and enthalpy distribution model in generalized curvilinear coordinates. Monthly Weather Review 131, 845-861. 